\title{
Criollos, mestizos e indios: etnias y clases sociales en México colonial a fines del siglo XVIII
}

INTRODUCCIÓN: EL PROBLEMA DEL MESTIZAJE Y SU HISTORIOGR A FIA

Mestizo: del bajo latín mixticius, mezclado (viene a su vez de mixtus, participio pasado del verbo miscere, mezclar).

"A los hijos de español y de india [...] nos llaman mestizos, por decir que somos mezclados de ambas naciones; fue impuesto por los primeros españoles que tuvieron hijos en Indias; y por ser nombre impuesto

- Ecole des Hautes Etudes en Sciences Sociales, París.

** псs у н-Universidad Autónoma de Puebla e nHEs-Universidad Nacional del Centro (Tandil, Argentina).
Juan Carlos Garavaglia* Juan Carlos Grosso**

por nuestros padres $y$ por su significación me lo llamo yo a boca llena, y me honro con él[...]" Garcilaso de la Vega, Comentartos Reales..., 1609.

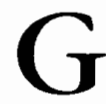
arcilaso de la Vega, el Inca, ya al fin de su larga vida y en su "exilio interior" andaluz, es uno de los primeros mestizos americanos que tan claramente asume no sólo su condición, sino también el apelativo de mestizo ( $\sin$ dejar de señalar que en Indias "lo toman por menosprecio").

Se puede decir que del mestizaje se habló desde siempre en la historiografia americanista. Si nos referimos a México, señalemos que los primeros estu. dios más serios fueron los de Aguirre 
Beltrán, centrados en la poblacion negra, ${ }^{1}$ y posteriormente los de Lyle McAlister $^{2}$ y los de Magnus Mörner, ${ }^{3}$ referido este último a toda América. Después de estos trabajos pioneros, a fines de la década de los setenta la discusión se avivó fuertemente. Los estudios de Chance y Taylor sobre Oaxaca, las críticas que a éstos hicieron McCaa, Schwartz y Grubessich, sumadas a las que realizó a su vez Patricia Seed y los trabajos de Rodney Anderson, son algunos de los hitos más destacados en esta nueva etapa de la discusión. ${ }^{4}$

Para que quede claro desde el comienzo, resumamos en pocas palabras los términos del problema, aun a riesgo de simplificar el debate: para algunos autores (Chance, Taylor y Anderson) la condición racial o étnica resultaría inadecuada (o insuficiente) para el análisis de la estratificación social de fines del siglo XVIII; ya en esa época la situación económica, o el estatus en términos de clase, ${ }^{5}$ tendría un peso

1 Aguirre Beltrán, Población, 1946.

2 McAlister, "Social", 1963.

3 Mezcla, 1969; podemos citar también el clásico libro de Lipschutz, Problema, 1975. El profesor Magnus Mörner ha retomado el análisis del problema del mestizaje en un reciente trabajo que lleva el título de "Etnicidad", 1990.

4 Entre los trabajos más recientes que han abordado el tema del mestizaje y que no son considerados en nuestro análisis por haber sido publicados cuando este artículo ya estaba redactado, cabe mencionar la revisión historiográfica realizada por Morner "Historia", 1992; el de Rabell, "Matrimonio", 1992, y el de Pescador, "Nupcialidad", 1992.

5 Desde luego que "raza", "etnia" y "clase" son conceptos cargados de significados tan complejos y contradictorios, que resulta sorprendente la facilidad con que los estudiosos los usamos sin ser conscientes de esas dificultades (y lo que decimos a lo largo del texto muestra sólo un tanto o más importante que la raza en la determinación de la posición de una persona en la sociedad colonial. Para los autores restantes, siguiendo la visión más tradicional, sería la condición étnica la que definiría la posición de un individuo en la estratificación social de la realidad novohispana. En realidad, si no cambiamos el enfoque del asunto, corremos el riesgo de caer en una discusión similar a la del sexo de los ángeles... (fundamentalmente porque en una situación como la de América colonial, los límites étnicos y los limites sociales nunca pueden tomarse como categorías contrapuestas, sino como sistemas de representación mutuamente significativos, como bien lo

aspecto de la cuestión); $\sin$ ir más lejos, un hijo de español e india sería un "mestizo" para el censista de Tepeaca en 1791 , pero sería un español que no merece el calificativo de "don" para el censista de Areco -en el río de la Plata - en $1778 \ldots$... Yhablando ahora de "clase", no debemos olvidar que una cosa es determinar a través de un padrón, un censo, o una serie de datos que surgen de diversas fuentes como inventarios suce. sorios, etc., una agrupación estadística significativa, y otra bastante diferente es una clase social, en cuya definición deberían entrar además otros elementos como una cierta conciencia de sus miembros de pertener a un mismo grupo y la capacidad de acción (económica, social o política) en función de esa percepción colectiva de pertenencia. Las observaciones de E. P. Thomp son, pese a los años transcurridos, siguen siendo muy importantes en ese sentido; véase Tradi. cd6n, 1979. En este estudio, cuando hablamos de clases nos estamos refiriendo a un concepto reducido cuasi exclusivamente a sus manifestacio nes puramente económicas, lo que indudablemente restringe en forma palpable su campo de aplicación, pero al menos el lector sabe de qué estamos hablando y, por supuesto, para nosotros "clase" es algo que va bastante más allá de una mera categoría socioprofesional. 
muestran hoy en día las dicusiones de los africanistas sobre este tema). ${ }^{6}$

Para evitar entonces esa trampa, es indispensable hacer un análisis más detallado de los términos del problema y de las posiciones enfrentadas. Chance y Taylor, en su trabajo "Estate and class in a colonial city: Oaxaca in 1792", publicado en $1977,{ }^{7}$ hablaron de un hecho que salta a la vista ante cualquier examen de los censos novohispanos de 1791 y 1792: una parte importante de los así llamados "españoles" por el censo, eran personas que tenían ocupaciones de bajo estatus y, por tanto, ellos dedujeron que, para finales del XVIII, la "raza" ya había dejado de ser el elemento clasificatorio central en la compleja estructura social de la colonia. La crítica de los tres autores señalados McCaa, Schwartz y Grubessich, publicada en la misma revista, apuntó sobre todo a ciertos problemas de tipo metodológico que tenía el estudio de Chance y Taylor y, fundamentalmente, a la representatividad real de la muestra utilizada por estos últimos. ${ }^{8}$

6 Ver, en especial, la discusión en Amselle, y M'Bokolo, Coeur, 1985 y Amselle Logiques, 1990. Amselle, en su trabajo "Ethnies et espaces", incluido en Coeur, afirma: "Plutôt que d'envisager les frontières ethniques comme des limites géographiques, il faut considerer cellesci comme des barrières sémantiques ou des systèmes de classement, c'est-à-dire en définitive comme des catégories sociales" (p. 34) [ "Más que considerar a las fronteras étnicas como límites geográficos, hay que considerarlas como barreras semánticas o como sistemas de clasificación, es decir, en definitiva, como categorías sociales"].

${ }^{7}$ Chance y Taylor, 1977 , pp. 454487 . Véase también el trabajo de Chance, "Ecology", 1981.

8 McCaa, Schwartz y Grubessich, "Race", 1979. Véase también el trabajo de McCaa, "Modeling", 1982.
Unos años más tarde, Patricia Seed publicó otro trabajo ${ }^{9}$ en el que afirma. ba que gran parte de la controversia le parecía poco consistente -inexistente son sus propias palabras-y que los historiadores poco habian hecho para definir con cierta precisión los términos de la discusión (en lo que no le faltan razones...). Pero nos parece que Seed está excesivamente apegada a sus propias fuentes cuando afirma que "la característica más notable de los criollos es su ocupación como comerciantes o como dueños de negocios, por lo que tienden a parecerse a los peninsulares más que a cualquier otro grupo racial". Pensamos que a lo mejor esto puede ser cierto visto desde la ciudad de México a mediados del XVIII - aun cuando tenemos fuertes dudas y habría que conocer las fuentes que ella utiliza para poder matizar esta afirmación-, pero para nada es la realidad que se puede percibir en Puebla o Tepeaca, como no parece ser la de Oaxaca según Chance y Taylor o la de Guadalajara, de acuerdo al estudio de Rodneý Anderson. ${ }^{10}$ En todos estos lugares, ya a fines del siglo XVIIr -la datación es de capital importancia- los límites étnicos y los sociales parecen sobredeterminarse e influirse mutuamente.

Una realidad de criollos ${ }^{11}$ muy po-

\footnotetext{
${ }^{9}$ Seed, "Social", 1982. Véase también Seed y Rust, "Estate", 1983.

10 Anderson, "Raza", 1988, pp. 5972.

11 En este trabajo llamaremos "criollos" a los españoles no peninsulares y que no poseen el apelativo de "don" en la documentación consultada. Desde luego que una discusión acerca de esta poco inocente partícula de "don" podría llevarnos muy lejos, pero no es éste el lugar ade. cuado para hacerla.
} 
bres, pobres, y algo menos pobres pero que se hallan socialmente bien lejos de "sus parientes los peninsulares", es algo tan evidente que parecería un esfuerzo inútil querer demostrarlo, pero la vigencia de esta polémica muestra que no lo es y que es indispensable aportar nuevos elementos para intentar ver más claro en esta discusión. Uno de los objetivos centrales del estudio que presentamos en las páginas que siguen es ése. Para nuestra suerte, el hecho de trabajar en dos puntas tan disímiles y diversas del imperio hispa. no -como son México central y el río de la Plata- nos posibilita ver algunas realidades con ojos diferentes. Lo que en la meseta poblana parece obvio, no lo es tanto visto desde la región rioplatense, y viceversa. Ello nos obligará a tener siempre presentes las determina. ciones temporales y espaciales de lo que el lector leerá en estas páginas.

\section{¿CUÁl ES EL PROBLEMA DEL "MESTIZAJE"?}

Ante todo, creemos que no hay un concepto de mestizaje, sino varios. La mayor parte de los autores se refieren a éste cuando hablan de la mezcla de diferentes "castas", según la terminología hispana colonial. Y ya que mencionamos a las castas, es bueno señalar que este concepto sociológico bastante preciso -aun si su significación profunda sigue siendo muy discutida- está alejado de la realidad colonial hispano y lusoamericana, aun cuando los testigos de la época acudan repetida. mente a esta palabra para hablar del fenómeno (y aquí casta quiere decir "grupo mezclado"). En efecto, si tomamos los elementos que Louis Dumont partiendo de la obra de Célestin Bouglé de 1908, considera como indispensables en el sistema de castas de la India, o sea, separación matrimontal $y$ de contacto entre los grupos concernidos, división del trabajo y ordenamiento jerárquico de los mismos, ${ }^{12}$ es fácil comprobar (y esperamos que nuestro estudio sea un buen ejemplo de ello) que lo que existió en América colonial no era, ni por asomo, un verdadero sistema de castas en el sentido que Dumont le da a este concepto. ${ }^{13}$

Nosotros nos referimos en este trabajo a las "castas" tomando la palabra con la acepción usual hispanoamericana de "grupo mezclado", que, paradójicamente, es exactamente lo contrario de la acepción sociológica actual de ese concepto en los estudios de los indianistas contemporáneos.

Por tanto, volviendo a nuestro proble. ma, comprobamos que el mestizaje generalmente hace referencia a las diversas mezclas raciales entre blancos, negros e indios, con todas sus infinitas variantes, resultado de los matrimonios interétni-

12 Dumont, Homo, 1979, pp. 36-37 (la obra de Bouglé es Essats, 1908). Es sintómatico que la palabra casta como sinónimo de grupo no mezclado, haya llegado a las restantes lenguas europeas muy probablemente desde el portugués y el español del siglo xvı.

13 "...pour qu'on puisse parler de caste il faut qu'il y ait système de castes en ce sens que l'ensemble des castes comprenne tous les membres de la société"; ["...para que se pueda hablar de castas es necesario que exista un sistema de castas, en el sentido de que el conjunto de las castas comprenda a todos los miembros de la sociedad"], cf. Dumont, Homo, 1979, p. 271 [cursivas del autor]. 
cos. Es obvio que éste es un aspecto de la cuestión, pero sólo uno, y probablemente el más conocido. Aunque, a nuestro entender, es sobre todo una consecuencla del fénomeno que estamos analizando, más que una causa.

Es decir, dejando de lado los casos -que en los primeros contactos suponemos que pueden haber sido más abundantes-de auténticas violaciones por parte de hombres blancos a mujeres indias, no parece serio suponer que toda la sociedad multirracial de la colonia se ha edificado sobre la violencia sexual (es decir, no parece serio pensar que, en esta sociedad, este infame mecanismo era más importante que en otras sociedades comparables de la época -en todo caso, no hay estudios específicos que nos permitan extraer conclusiones al respecto). Nos parece que pensar esto es en realidad valorizar en forma excesivamente negativa a esta sociedad y, probablemente, idealizar un tanto la nuestra...

Nosotros, por el contrario, pensamos que (con la especial salvedad del caso de los esclavos) ${ }^{14}$ la mayor parte de las uniones sexuales entre individuos de distintos grupos raciales, son el resultado del acercamiento entre dos personas, de su proximidad cultural y social, del hecho de compartir situaciones, lugares de encuentro, lenguas, gestos. Y, finalmente, de todo eso que forma parte en las sociedades humanas del complejo mecanismo de la seducción.

Por supuesto hemos dicho "la ma-

14 Para un tratamiento excelente del problema en Cuba, ver la edición castellana de Stolke, Ractsmo, 1992. yor parte de las uniones sexuales" y no todas. Como ya dijimos, debemos exceptuar de este universo al mundo de los esclavos donde, casi por definición, el problema de la violencia sexual parece mucho más determinante. Pero de todos modos, muy a menudo-siempre fuera del ámbito específico de las plantaciones- la diferencia que encierran las palabras "negro", "mulato", "pardo", "moreno" y otras, no siempre se relaciona con el grado de mezcla racial entre blancos e indios y estos grupos de ascendencia africana, sino que también suele hacer mención al problema de la percepción, por parte de los testigos, de grados diversos de aculturactón. Pero esto hay que analizarlo cuidadosamente en cada lugar. No es lo mismo la situación de un "pardo" de una chacra o de una estancia de la campiña de Buenos Aires -esclavo, pero capataz y a cuya orden trabajan los peones libres- que la de los esclavos en una hacienda venezolana o una fazenda bahiana. También debemos exceptuar los casos, repetidos hasta el infinito en las fuentes y ampliamente retomados por la literatura (y las radionovelas y telenovelas latinoamericanas...), del gran propietario rural que goza del derecho "de pernada" entre las mujeres pertenecientes a las familias de "sus" indios o peones.

Para evitar cualquier equívoco, debemos decir de entrada que a nosotros, en este estudio, nos preocupa sobre todo la situación en la que ambos protagonistas de la futura relación no guardan una fuerte distancia social entre sí. De ellos vamos a hablar fundamentalmente en el curso del trabajo. Nuestro análisis, además, está casi exclu- 
sivamente centrado en el ámbito de una pequeña villa provincial del valle poblano. Es decir, las páginas que siguen se refieren en particular a ese ámbito privilegiado del mestizaje, que fue la vida urbana del último siglo colonial.

Volvamos entonces al hilo de nuestro argumento. El hecho de que un arriero, tenido por español y de limitados recursos, durante sus ajetreos sema. nales entre una pequeña villa y una ciudad no muy lejana, pase repetidas veces por la puerta de una choza donde una joven indigena lo espía, puede conducir a un primer acercamiento entre am. bos. Si la lengua o los gestos (las sonrisas, los guiños) lo permiten, comienza aquí a haber un intercambio de palabras o de gestos. Este intercambio pue. de o no terminar en una unión sexual entre las dos personas; lo importante en este contexto es que el mestizaje en realidad es previo a esa unión sexual, el mestizaje es justamente el mecanismo social que posibilita esa relación sexual, fruto de la cual puede ser un hijo "mestizo". Hay una serie de hechos previos, insistimos, a ese encuentro que muy probablemente serán -si los individuos en cuestión se "gustan" y iqué poco sabemos sobre la historicidad de este concepto!- acelerados por el hecho mismo del encuentro.

En realidad la relación que se comienza a tejer entre estos dos seres $-\mathrm{y}$ sobre todo la propia relación sexuales uno de los elementos que más juegan en función de un progresivo acercamiento entre ellos. Los nuevos gestos que se aprenden, las nuevas palabras que se usarán para designar emociones y cosas ya conocidas o que se comienza ahora a conocer; esas mismas palabras, un poco más tarde, si la relación dura algún tiempo, servirán para contar anécdotas familiares o de los vecinos circundantes, historias de anteriores aventuras, cuentos de aparecidos y de dioses. Antes del nacimiento mismo del hijo que la mujer espera con aprensión, el mestizaje se ha ido acentuando, y ese fruto, como decíamos, no es más que un resultado de todo el proceso. Resultado que por supuesto, lo multiplica y lo acelera a su vez. Esos hijos que hablarán casi indistintamente las dos lenguas, conocerán historias de un lado y del otro y bascularán hacia una cultura o hacia la otra; al menos públicamente, pues quién puede saber qué pasa en su fuero interno, donde luchan las imágenes del padre y de la madre yde sus respectivos mundos.

Agreguemos ahora otro ejemplo hipotético pero, como verá el lector en el texto, estrictamente apegado a la realidad de los datos que poseemos sobre la villa de Tepeaca.

Imaginemos a tres familias que conviven en la misma casa. Una de ellas es criolla, otra está compuesta por castizos y mestizos y la restante por una criolla y un cacique. De los tres cabe. zas de familia, dos son tejedores y uno es herrero; uno de los hijos, el mayor, es un arriero. Los hijos restantes, unos cinco chicos de edades que van de los 6 a los 12 años, conviven en el mismo espacio, charlan una o dos lenguas, se cuentan historias, cotidianamente jue. gan y maquinan diabluras en conjunto. Más tarde, los varones comenzarán a aprender el oficio de los padres o a pensar en otros horizontes, ya sea siguiendo el camino del hermano arrie- 


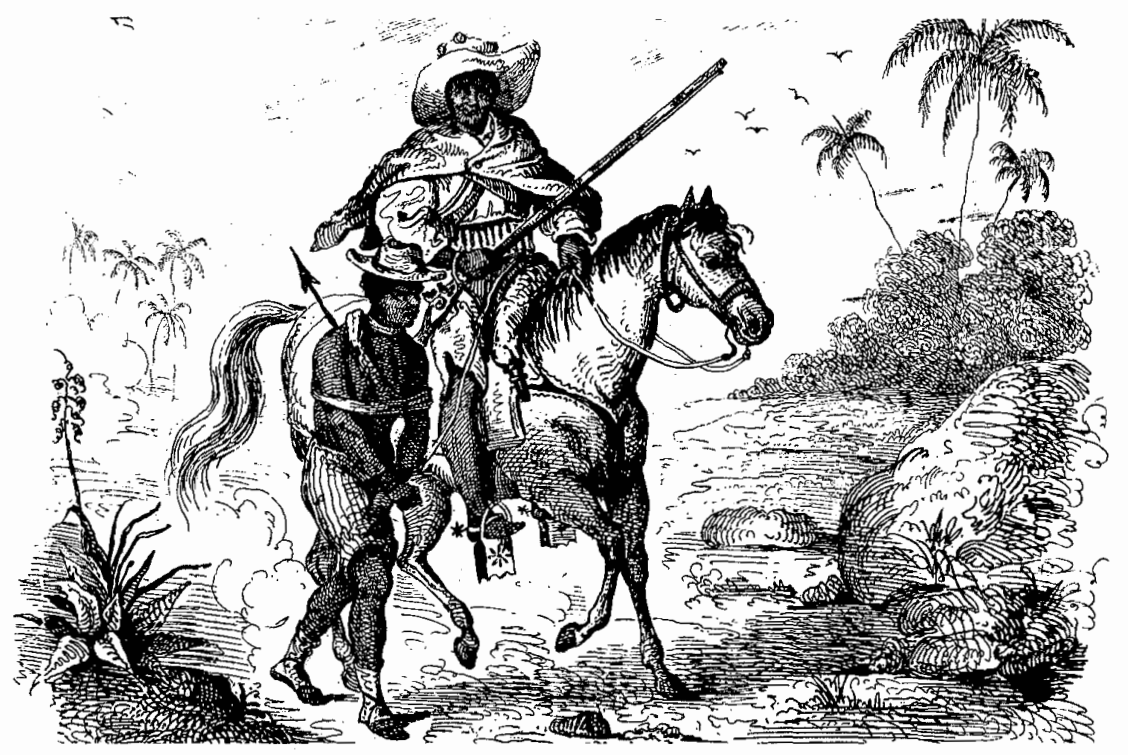

ro, o para integrar el contingente incesante de migrantes masculinos en busca de trabajo. Y las mujeres al catecismo y a hilar, como lo habían hecho sus madres veinte años antes. ¿Es asombroso suponer que los futuros partners sexuales de estos chicos surjan de un ambiente similar al que han vivido? ¿Que los hombres elijan como esposas a criollas, castizas o indias que se visten con el mismo rebozo, hablan y se expresan como lo hacían sus madres o que la mujeres busquen como maridos a criollos pobres, mestizos $o$ indios que ejercen oficios parecidos a los que tenían sus padres?

Todo eso constituye justamente el mecanismo del mestizaje. Para decirlo con las propias palabras de Fredrik Barth: [...]los grupos étnicos persisten como unidades significativas sólo si van acom. pañados de notorias diferencias en la conducta, es decir, de diferencias culturales persistentes. No obstante, cuando interactúan personas pertenecientes a culturas diferentes, es de esperar que sus diferencias se reduzcan, ya que la interacción requiere y genera una congruencia de códigos y valores; en otras palabras, una similitud o comunidad de cultura. ${ }^{15}$

Y desde luego que el medio de vida urbano no hace más que acentuar y acelerar este proceso. Ahora bien, el hecho de que este mecanismo funcio. ne de tal modo, no implica que $a$ todos les sea por completo indiferente la ubi-

15 Barth, Grupos, 1976, p. 18. 
cación en alguno de estos "casilleros" socioétnicos.

Los antropólogos y los sociólogos insisten hoy en día en considerar a la autodefinición como uno de los elementos centrales en la constitución de los límites étnicos; ${ }^{16}$ pero, como es obvio -nuestros "informantes" duermen el sueño de los justos- no siempre es fácil un análisis histórico de este hecho. Y más de una vez, las fuentes nos hablan de los diversos problemas que suscitaron a los testigos las distintas manifestaciones de ese mecanismo de "autodefinición".

En 1796 un funcionario de Guanajuato ocupado en reclutar milicianos, y por tanto, altamente sensible al problema de la definición de indio (éstos no podían ser reclutados), afirma:

[...] como el mayor número de la gente que compone el pueblo bajo de esta Nueva España es de castas no limpias y sí mezcladas unas con otras por el ningún reparo que tienen en sus enlaces

16 Y esto se percibe hoy no sólo en los estudios sobre grupos étnicos de sociedades no europeas, sino que el fenómeno también puede ser de gran utilidad para el estudio de algunas minorías "étnicas" europeas; nos parece sintomática la posición de Dominique Schnapper acerca de la condición de "ser judio" hoy en Francia: "No es la cantidad de abuelos judíos lo que distingue socialmente a los judios de los no judíos, sino su voluntad de continuar afirmando, de alguna forma $u$ otra, la identidad judía de sus abuelos..." Véase Schnapper, "Limites", 1987, pp. 319-332 (si bien hay que reconocer que la terrible experiencia de los años del nazismo en Europa nos muestra que independientemente de la autodefinición de "judio", había otros que podían determinar su ubicación en esa categoría y esto complica entonces la aparente simplicidad de la cuestión de "ser judio", como bien lo señaló hace años Jean-Paul Sartre). matrimoniales [...] es muy dificil hacer los alistamientos de milicias de sólo españoles [...] Todo esto parece que estaría remediado con ocurrir a los libros parroquiales [...] pero lejos de aclararse... se encuentran nuevas dificultades, así por los repetidos descuidos que hay en los asientos como porque al tiempo de bautizarlos dicen los acompañantes que son españoles no siendo[... $]^{17}$

Las cursivas son nuestras, y dan en el blanco en uno de los problemas fundamentales ya enunciados: la autodefinición. Para este testigo resulta menos importante el concepto que los propios individuos tienen de su posición en la sociedad, que el esfuerzo para ubicarlos en una supuesta clasificación objetiva, que obviamente no existe en la realidad. Como ocurre en otros contextos, podemos decir que el nudo de nuestro problema es que existe siempre en el proceso -eternamente inacabado y siempre incompleto- de constitución étnica un continuum de auto y endoclasificación. ${ }^{18}$

Las palabras preliminares del censo de 1791 de Tepeaca nos parecen también sintomáticas en este sentido:

Las familias de la gente común, por lo regular ponen al arbitrio de quien se lo pregunta las clases a que corresponden y, menos preocupados o más humildes que otros que finjen lo que no son, es

17 "Antonio Pérez Gallardo (Guanajuato), al virrey Branciforte (México), 13 de mayo de 1796", Archivo General de la Nación (AGNM), Indiferente de Guerra, vol. 384-4.

18 Véase, en relación con los diversos componentes históricos de la identidad judía y este aspecto de la cuestión, las reflexiones de Amselle, Logiques, 1990, pp. 36-37. 
necesario informarse de lo que fueron sus padres para deducir su calidad, y les es indiferente que resulten españoles castizos, mestizos, defendiendo sólo el degenerar en pardos $o$ indios tributarios... 19

Es decir, para los individuos que el censista llama pudorosamente "gente común", es decir, los pobres, les era casi indiferente saber en qué lugar estaban de la compleja clasificación que esta sociedad barroca había ideado, siempre que no se los confundiera con individuos de sangre negra -nuevamente el censista agrega un verbo muy poco inocente: "el degenerar" en pardos- o con indios tributarios. El primer aspecto es general en toda A mérica hispana, y desmiente una vez más el candor con que habitualmente se trata el tema del prejuicio racial respecto a los africanos en Iberoamérica. El mote de "mulato" erā -y en muchos casos, sigue siéndolo-uno de los insultos más fuertes desde California hasta la Patagonia.

En cuanto al segundo aspecto, la relación con los indios "puros", la cosa nos parece bastante más compleja, y debe haber variado mucho de lugar en lugar, incluso en el México central. Además, lo que habría que saber también es si un indio de Tecali se define a sí mismo genéricamente como indio o como miembro de un grupo parental en el marco de la comunidad de Tecali... Parecería que, para el testigo español, todo los "indios" tienen algo en común (son indios, obviamente... ), pero dudamos que esta visión sea com-

\footnotetext{
19 AGNM, Padrones, vol. 38.
}

partida de idéntico modo por los propios interesados.

$\mathbf{Y}$ de todos modos, no olvidemos que un estudio de campo realizado hace unas decenas de años por dos antropólogos en el área de Puebla, nos relata cómo en San Andrés Calpan, en plena meseta poblana, la "gente de razón" -inunca tan expresivo este giro! - llama a los indígenas con el inequívoco apelativo de "cerraditos"...20 Y no parece inútil recordar que el "naco" con que adornan en nuestros días los habitantes del Distrito Federal a sus concitadinos que a sus ojos parecen menos refinados, viene de totonacos. Desde luego que los ejemplos de las sociedades contemporáneas más diversas y que el ya referido $F$. Barth, por citar uno entre varios, ha estudiado en profundidad, nos muestran que el problema de los "límites étnicos" -y sus consecuencias en cuanto al prejuicio racial- es algo complejo y cuasi universal en las sociedades humanas.

Como podrá observar el lector, en este estudio trabajaremos con algunos datos que surgen de cuatro sistemas de representación social que se entrecruzan. Ante todo, el parentesco, en todas sus formas y manifestaciones (parentesco sanguíneo, por alianza y religioso/ritual). Asimismo la residencia, es decir, la posibilidad o no de que las personas en cuestión circulen y convivan dentro de ciertos espacios: una casa, una calle, un barrio. Seguidamente, hablaremos de la afinidad ocupacional, o sea el hecho de compartir un mismo oficio $u$ oficios que se hallen muy próximos. Y finalmente, las carac-

\footnotetext{
${ }^{20}$ Nutini y Barry, Pueblos, 1974.
} 
terísticas étnicas tal como son percibidas por las fuentes de la época. Claro que esta enumeración es sólo eso, una enumeración, y no presupone ningún tipo de jerarquía a priori en el marco de estos sistemas de representación social. Dado que nuestra ciudad es un área expulsora más que receptora de migraciones, casi no analizaremos otro sistema de representación: los vínculos de paisanaje. Si bien hemos hallado algunas excepciones, estos vínculos tuvieron nada más que una moderada influencia en el caso que estamos estudiando.

Clases SOCIALES Y ETNIAS: ESTRUCTURA ETNICA Y OCUPACIONAL EN LA VILLA DE TEPEACA EN 1791

Nos centramos en las cifras de esos años porque ellas nos permitirán un análisis mucho más afinado de la estructura étnica y ocupacional de la ciu. dad de Tepeaca. Según el censo de 1791, había en ese entonces aproximadamente 212060 habitantes, sin contar

21 Decimos "aproximadamente" porque los indigenas de la villa que hay censados en el padrón de 1791 cuentan con varios casos de "familias indígenas" -sin especificar la cantidad de miembros- y de personas que ocupan a "varios criados y criadas indios", donde tampoco se especifica el número (recordemos que en el caso de Tepeaca el padrón de Revillagigedo sólo censó de una manera más o menos sistemática al sector de la población no indígena). Hemos hecho el siguiente cálculo: hay 93 individuos que forman parte de familias mixtas o que viven en casas de otras familias; 60 familias a las que hemos aplicado el mutiplicador 3.30 -tomado de los promedios por familia del padrón de indios de 1792-, once casos de criados y otros diez de "varios criados..." los indígenas de los barrios, en el perímetro de la villa. En 1792 se censaron unos 1850 indigenas en los barrios indios. ${ }^{22}$ Es decir, estamos en una cifra de alrededor de 3900 habitantes; empero, como es probable que una parte de los 332 indigenas que hemos detec. tado habitando en el casco céntrico de la ciudad (sea como "criados" agregados a familias españolas, como miembros de familias mixtas, o simplemente integrando familias indigenas) hayan sido registrados por el padrón de 1792 en sus barrios originarios donde deberían estar censados como tributarios, es preferible optar, como mero título estimativo, por una cifra conservadora de unos 3700 habitantes. De todos modos, el censo de 1791 trae una buena documentación para analizar la estructura étnica de la villa.

Ahora bien, si relacionamos estos datos de 1791 con los de 1792 , referidos a la población indígena de los barrios, tendríamos los siguientes porcentajes puramente estimativos, por las razones ya apuntadas: indios $53.5 \%$, peninsulares y criollos $23.4 \%$, mestizos $12.7 \%$, castizos $5.5 \%$ y mulatos $2 \%$. En resumidas cuentas, hay una leve mayoría de indios en la población, frente al $24 \%$ de peninsulares y criollos y el $23 \%$ de castas aproximadamente (hay que señalar que muchos de los casos sin especificar se refieren a castas muy probablemente). Esta es una villa de raigambre indígena como sabe-

que hemos multiplicado por tres para pecar de pesimistas. El resultado es esa cifra aproximativa de 332 indigenas para el casco de la villa; véase AGN, Padrones, 38.

22 Véase AGN, Genealogía, rollo 3558. 
Cuadro 1. Estructura étnica del casco de la villa de Tepeaca en $1791^{\mathrm{z}}$ $\begin{array}{lll}\text { Hombres } & \text { Mujeres } & \text { Total }\end{array}$

$\begin{array}{lrrrr}\text { Peninsulares } & 12 & 1 & 13 & 0.6 \\ \text { Criollos } & 393 & 462 & 855 & 41.5 \\ \text { Mestizos } & 226 & 243 & 469 & 22.8 \\ \text { Indios } & - & - & +332 & 16.1 \\ \text { Castizos } & 106 & 98 & 204 & 9.9 \\ \text { Mulatos } & 38 & 35 & 73 & 3.6 \\ \text { Sin datos } & 42 & 72 & 114 & 5.5 \\ & & & & \\ \text { Totales } & 817 & 911 & +2060 & 100.0\end{array}$

- Sin tomar en cuenta a los barrios indígenas.

Cuadro 2. Ocupaciones de la elite, 1791

Peninsulares Criollos Criollos Total

Comercio

Comerciantes

Tendera

2

"dones"

Cajeros

4

7

13

1

Agricultura

Labradores

1

2

3

Burocracia

Estado/milicia

Colec.diezmos

6

Escribs. y otros

Clero

1

3

5
2
4
4

11

Totales

12

$\begin{array}{llll}21 & 17 & 50\end{array}$

1

3

$5 \quad 12$

CRIOLLOS, MESTIZOS E INDIOS 


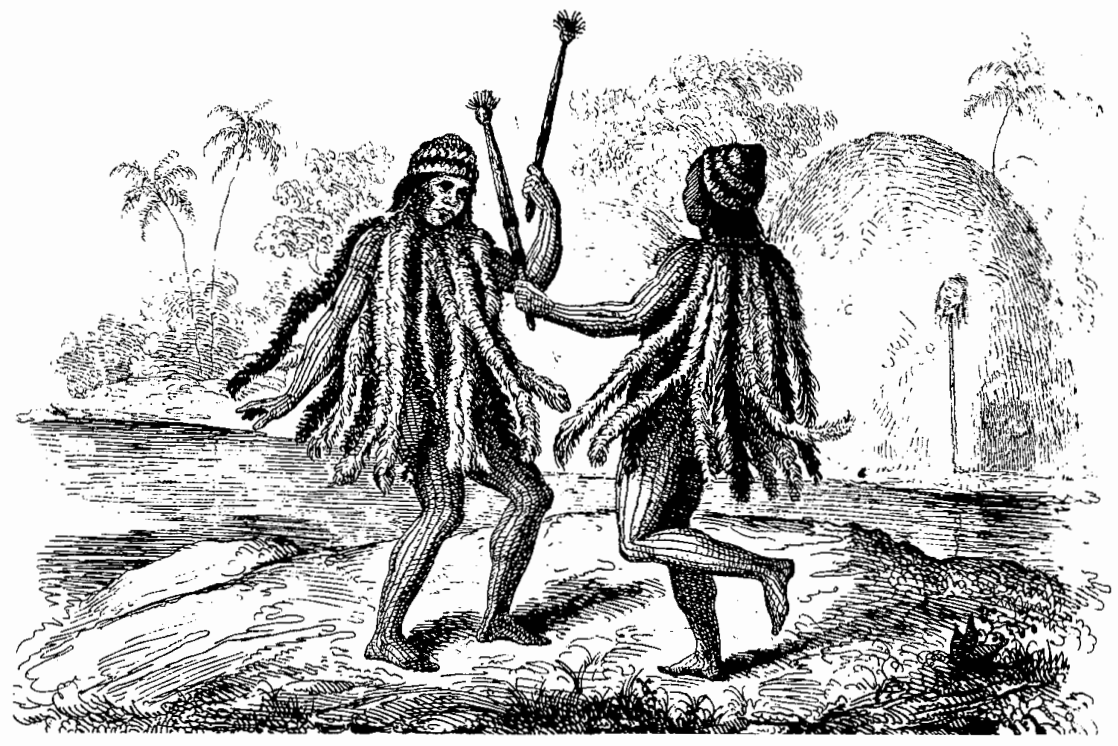

mos, pero ya a fines del siglo XVIII ha sufrido un intenso proceso de mestizaje socioétnico. Volveremos más adelante sobre este aspecto de la cuestión.

\section{EL SECTOR DOMINANTE}

El censo de 1791 clasifica como "don" a sólo el $2.1 \%$ del total de la población empadronada de Tepeaca; de éstos, $2.8 \%$ son hombres y $1.5 \%$ mujeres. ${ }^{23}$ Indudablemente el censista usó en forma muy restringida esta calificación, no sólo por la baja feminización. del

${ }^{23}$ Comose observa, estos porcentajes no son coincidentes con los del cuadro 1 antecedentes, pues en él hemos agregado a los indígenas; éstos no están contabilizados en el resumen final del censo, dado el carácter militar del mismo. "don", lo que es bastante inusual y por no utilizar este apelativo para los hijos menores de los "dones", sino porque muchos individuos que en otro tipo de documentación suelen contar con este tipo de apelativo aquí no lo llevan. Casos como los de Gerónimo Santander o José Acevedo de la Gándara, ambos comerciantes a quienes los registros notariales y los Libros de Alcabala otorgan siempre este apelativo, son quizá los más llamativos. En este caso es muy difícil saber cuál fue el criterio que guió al censista. De todos modos este reducido grupo de los "dones" es indudablemente el sector dominante de la sociedad de la villa. Hay que notar que un porcentaje importante de estos "dones" son peninsulares, pero que no todos los peninsulares (Gerónimo Santander es nuevamente un buen ejem- 
plo de ello) gozan automáticamente de esta prerrogativa.

El mundo del trabajo:

las ocupactones de la elite

Veamos los datos para el sector socialmente dominante de la población de la villa y sus actividades (cuadro 2 ).

No puede asombrarnos que la abrumadora mayoría de los miembros de la burocracia estatal y del clero pertenezcan al sector de los peninsulares y al de los criollos "dones", y que sólo una tercera parte de los cargos y ocupaciones considerados de elite estén desempeñados por criollos que no tienen el apelativo de "don". Si sumamos a estos 50 individuos que en su gran mayoría son cabeza de familia, aquellos que mantienen criados indigenas o esclavos (que no están incluidos entre los de estas ocupaciones y no están agraciados con el título de "don" y en realidad son sólo dos familias más), tenemos claramente representada a toda la elite urbana de esta pequeña villa poblana. Por supuesto hay que recordar que la mayor parte de los hacendados del hinterland residen en sus haciendas o -esto ocurre sólo en un par de casos- en la capital regional, la ciudad de Puebla, y por eso casi no aparecen contabilizados en estos datos referidos a la villa.

\section{Los criollos}

Como veremos a través de los datos ocupacionales, el grupo criollo tiene en su interior grandes diferencias sociales, pero no hay duda de que ha habido un proceso de crecimiento de este sector; según los datos del padrón de 1777 , había en toda la parroquia unos 874 españoles $^{24}$-tomando en cuenta a "dones" y criollos juntos-y en 1791 en la jurisdicción parroquial tenemos a unos 1 331. Es decir, los españoles han crecido más de $50 \%$ entre esas dos fechas, mientras que los mestizos y los castizos sólo lo hacen en $28 \%$; pero obviamente estas cifras están escondiendo un proceso de "blanqueamiento" y de pasaje de individuos de una categoría a la otra, como estudiaremos en su momento.

Para ello, nada mejor què observar las pirámides de la gráfica 1; en ellas hemos colocado separadamente a los solteros españoles y a los de las castas. Es visible una marcada diferencia en la primera cohorte, la que corresponde a las edades de hasta 9 años. Este "envejecimiento" de los españoles y esta gran cantidad de varones de menor edad entre las castas, puede querer decir que estamos ante un proceso de mestización, que muchos de estos jóvenes serían fruto de uniones libres. Este proceso resultaría así ocultado por otro tipo de fuentes, como es el caso de los registros parroquiales donde sólo aparecen los casos "legales". En todo caso, la cuestión está abierta a la discusión y volveremos sobre el tema al estudiar concretamente el problema interétnico.
24 AGr-México, 2578. 
Gráfica 1. Ciudad de Tepeaca: solteros, 1791
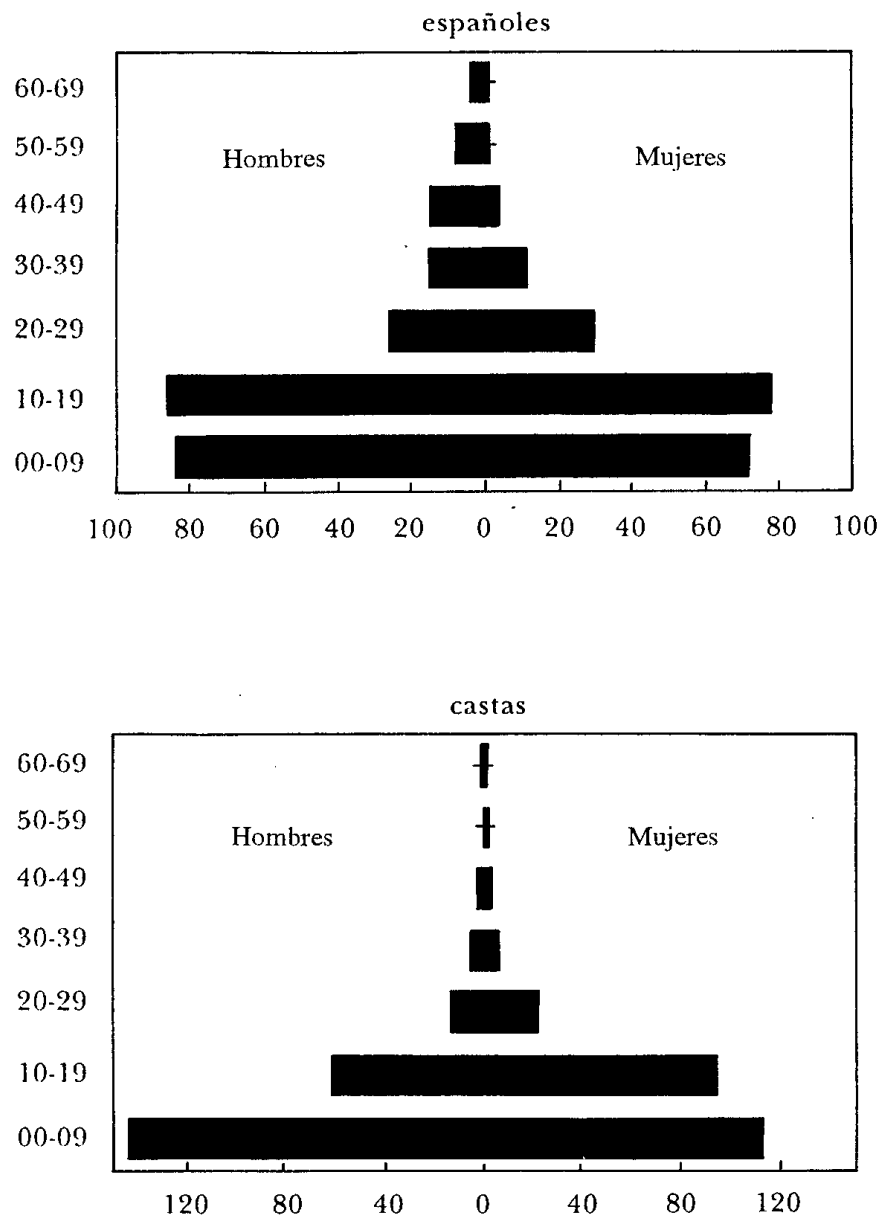
Las "castas"

Si bien las cifras generales de los censos de 1777 y 1791 para toda la parroquia hablan de una disminución relativa del peso de estos grupos frente a los criollos, hemos visto que esto puede ser considerado un fenómeno de "blanqueamiento" debido a los diversos criterios de los censistas y al tipo de declaraciones que efectúan los mismos individuos censados. De todos modos, con $20 \%$ del total estimativo de la poblacion de la villa, las "castas" tienen ya un lugar ganado en la sociedad local. No hemos encontrado para Tepeaca sino casos muy aislados en los que se utilice la compleja terminología clasificatoria para las diversas mezclas raciales, y los términos más usuales son mestizo, castizo y mulato (o pardo libre). Pero desde luego que, visto desde el río de la Plata, este sistema aparece como muy complejo todavía; en efecto, en la campiña o en la ciudad de Buenos Aires sólo se habla de indios, negros, mulatos y españoles, siendo la terminología de castizos y mestizos algo de muy rara utilización en los censos de la época.

\section{Los indígenas}

El sector más importante, numéricamente hablando, y también el más sumergido. En una villa indígena, pero donde la comunidad juega un papel poco relevante (producto probablemente de una situación que se arrastra desde los tiempos prehispáni- $\cos )^{25}$ y en donde la antigua nobleza ha ido perdiendo gran parte de su riqueza en tierras a manos de los españoles desde fines del sigloXvi ${ }^{26}$ (como ha ocurrido, por otra parte, en casi toda la región), los indígenas han ido creciendo según las cifras de los padrones de 1771 y 1792 a una tasa del $30 \%$, intermedia entre la de los criollos y la de las "castas".

Como ya dijimos, la gran mayoría de los indígenas que conformaban parte de la población de la villa de Tepeaca, vivian en los barrios de la periferia. Aun así, hacia 1790 habitaban en el casco urbano de Tepeaca más de 330 indígenas, que representaban una parte no despreciable de sus pobladores (16\%). Parte de este contingente de indios "urbanos" integraba las 60 familias indigenas registradas por el padrón de 1791 , a las que se le sumaban el centenar de individuos de ambos sexos que formaban parte de familias "mixtas"; el resto de la población indígena del casco urbano estaba compuesta por unos 40 criados y sirvientes que trabajaban y vivían en casas de familias españolas, como ya dijimos.

25 Tal es la opinión, autorizada por su excelente trabajo, de Hildeberto Martínez, Tepeaca, 1984, y si bien no podemos en este trabajo extendernos sobre el tema -lo haremos en un estudio en preparación-, es sintomático que este libro y sus posiciones teóricas sobre este importante problema no hayan merecido casi ningún comentario de los especialistas.

${ }^{26}$ En 1704 el representante de los labradores de Tepeaca sostuvo que todas las tierras que componían las haciendas "traen el origen de los naturales, caciques y principales, que fueron en ella, cuyas ventas las otorgaron con solemnidad y circunstancias dispuestas por las Reales Cédulas..."; AGNM, Tierras, 2730.1 
Los caciques y principales constituían un sector minoritario de esta población indigena "urbana". Si bien compartían el uso del "don" con los españoles de mayor relevancia social, ninguno de ellos poseía una fortuna comparable a la de los miembros de la elite local; los testamentos e inventarios de bienes nos los presentan como propietarios de casas y solares urbanos, de parcelas de tierras y pequeños hatos de ganado $y$, excepcionalmente, como dueños de alguna finca. ${ }^{27}$

Con respecto a los indios "comunes" que vivían en el casco urbano de Tepeaca formando parte de familias in dígenas o "mixtas", la documentación, como era de esperar, es escasa o muy parca. Aquellos pocos que dejaron sus huellas en los registros notariales, son

${ }^{27}$ Así, por ejemplo, don Pedro Martínez, "cacique principal y gobernador de los naturales que ha sido varias veces de esta ciudad ${ }^{n}$, en 1777 declaró como sus bienes la casa donde vivía con un solar contiguo y tres "pedazos de tierras" plantados con magueyes que los había adquirido por compra; a su hijo legítimo, que era "presbítero de este obispado" le había costeado sus estudios y la ordenación, en tanto que a un hijo natural to había habilitado con 32 pesos en reales, "un pedazo de tierra" con magueyes valuado en 24 pesos y 30 ovejas; en un segundo testamento, redactado en 1793, los bienes declarados fueron los mismos. AGNP, Tep. 1777 y 1793 . Otros casos de "caciques principales" de Tepeaca son: don A lejandro de Silva, dueño de la casa donde habitaba en la ciudad, de varios "solarcitos" con plantaciones de magueyes situados en los barrios, unas pocas cabezas de ganado y dos caballos de silla (AGNP, Tep. 1777); don Francisco Mendoza, propietario de un rancho en las cercanías de la ciudad de Tepeaca (AGNP, Tep. 1784); don Domingo Cortés Ximenez, cuyos únicos bienes los constituían su casa con "un solarcito con magueyes" y tres "pedazos de tierra" de un almud de sembradura (AGNP, Tep. 1803). los propietarios de humildes casas, de solares urbanos poblados con magueyes, de algunas cabezas de ganado menor y de "pedazos de tierras";28 aún más excepcional es la documentación que nos presenta a estos indios urba. nos como artesanos, aunque no sería aventurado pensar que aquellos que vivían en el seno de una familia mestiza o de españoles pobres, donde los varones se desempeñaban como artesanos, participaran en las mismas actividades productivas.

Respecto a los indios de los barrios, tampoco son muy explícitas las fuen. tes de que disponemos. Sabemos que algunos de ellos también poseían algunos bienes además de las tierras de re. partimiento, o bien eran arrendatarios de pequeñas parcelas en las fincas cercanas; ${ }^{29}$ otros eran tejedores que trabajaban para algunos maestros criollos, como el caso del indio tributario José Pío Amaro, ${ }^{30}$ o poseían sus propios telares donde manufacturaban los tejidos que luego vendían en el tianguis semanal de la misma villa o entre-

28 José Guillermo Olivos, un indio natural de la ciudad de Puebla avencindado en Tepeaca, era propietario de la casa donde moraba (que había sido adquirida por su esposa, también india, con los 90 pesos que había recibido de una herencia), de otra "casita" en la misma villa, y de dos solares poblados de magueyes. AGNP, Tepeaca, 1791.

29 Así, por ejemplo, el indio Cruz Sente, en el testamento redactado en 1790 , declaró como bienes propios "la vivienda de jacal de su habitación" edificada en un solar de repartimiento, $1200 \mathrm{ma}$ gueyes, un "solarcito", doce ovejas y tres carneros padres, dos burros y "un almud de maíz" que tenía sembrado en una parcela de la hacienda de Santa Ana por el que pagaba un arrendamiento de 10 reales. AGNP, Tepeaca, 1790.

30 AGNP, Tepeaca, 1800. 
gaban a aquellos comerciantes que los habilitaban. Casi un tercio de la pobla. ción indígena de la parroquia vivía, según el padrón de 1777, en los pueblos de su jurisdicción: este sector de campesinos indígenas constituía la principal fuente de mano de obra donde se reclutaban los tlaquehuales y meseros que reforzaban, en ocasión de los momentos más altos del ciclo agrícola, la fuerza de trabajo estable que poseían las haciendas vecinas.

\section{Las "castas", los criollos y el mundo del trabajo}

El censo de 1791 trae interesantes datos sobre la estructura ocupacional de la ciudad; lamentablemente, como ocurre con todos los censos ordenados por Revillagigedo, no hay datos sobre la población indígena. Además, sólo muy ocasionalmente las mujeres poseen ocupación señalada en el censo, cuando sabemos que éstas jugaban un papel de primera importancia en muchas tareas anexas a la tejeduría que era, de lejos, la actividad más destacada de la villa de Tepeaca a fines del XVIII, como también en otras actividades. ${ }^{31}$ De todos modos, tal como lo hi-

31 Unos pocos ejemplos, tomados de los inventarios notariales, nos muestran claramente la función económica de la mujer en diversos contextos. Marcela Candelaria de los Reyes, en 1780 , es una castiza e hija natural que posee seis arrobas de lana "para beneficiar" y varios solares sembrados con magueyes (AGNP, Tepeaca, 1780, fs. 54-56). María Josefa Huerta, española, tiene en 1795, amén de su solar en donde vive, pobla. do de magueyes, un chinchorrito de ganado ovejuno con 47 cabezas, y debe a varios comercian- cieron otros autores para Oaxaca, Guanajuato, León y Querétaro, creemos que los datos son de gran utilidad para un mejor conocimiento de la estructu. ra ocupacional novohispana y para atacar el problema que nos preocupa mas centralmente.

Lo primero que llama la atención en el cuadro 3 es la relativamente alta participación de los criollos en casi todas las ocupaciones artesanales, ocupaciones que para nada parecen estar reservadas a los sectores considerados "racialmente" inferiores de la población. Aquí la aserción de Patricia Seed, que hemos citado en las páginas precedentes, no parece tener validez. Solo los artesanos gamuceros, zapateros (que no representan sino una clara minoría) y en mucho menor medida los curtidores, tienen una presencia dominante o muy importante de las "castas" frente a los criollos.

Por otra parte, entre los tratantes - ocupación que suele considerarse de un estatus similar a la de los artesanos de nivel superior o, según Brading, como formando parte de la "clase trabajadora alta" - 32 los criollos están levemente subrepresentados, de acuerdo a lo que podría esperarse por el porcentaje de su participación en el total de la población masculina, en tanto que los

tes unas cortas sumas de dinero (AGNP, Tepeaca, 1795, fs. 21 vta.-23). La española Pascuala María López, con tres hijos naturales, posee no sólo su solar con magueyes, sino que en un terreno de un vecino ha plantado otros magueyes que explota (AGNP, Tepeaca, 1806, fs. 128 vta.-130 vta.). Finalmente, hablemos de Josefa Gutiérrez, espa. ñola, tejedora con su solarcito, su telar y algunas baratijas más (AGNP, Tepeaca, 1794, fs. 22 vta. y 1817, f. 200).

32 Brading, "Grupos", 1972, p. 477. 
Cuadro 3. Selección de ocupaciones y estructura étnica, $1791^{\mathrm{a}}$

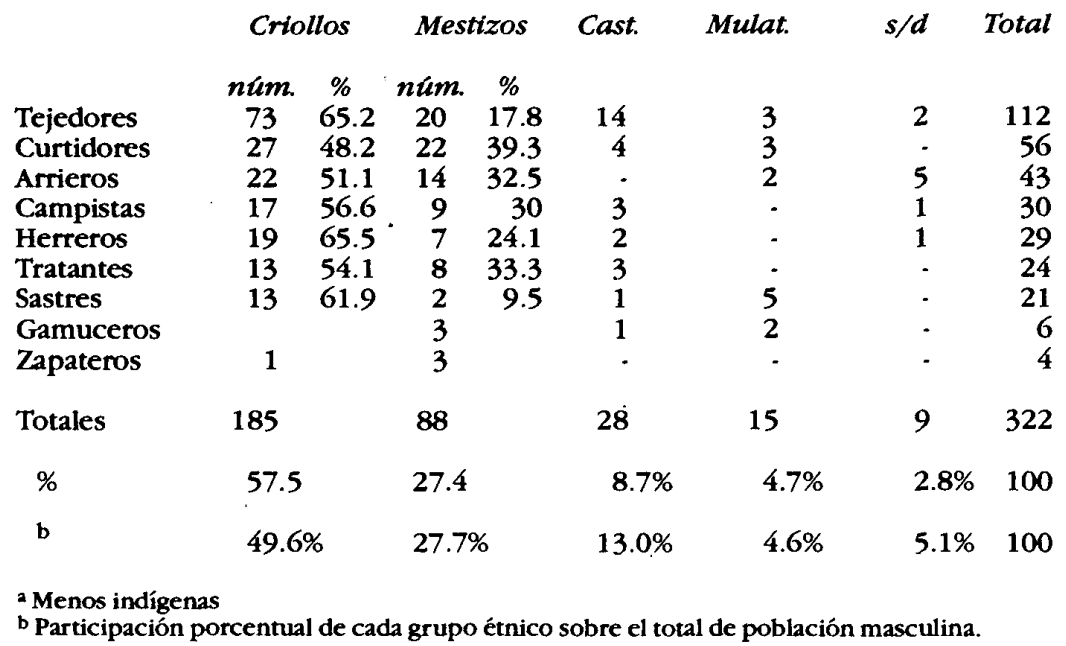

mestizos tienen una mayor participación que la esperada según el mismo criterio. En cuanto a los castizos y mulatos, su escaso número impide mayo. res consideraciones; quizá deba subrayarse la "preferencia" de los castizos por el oficio de tejedor (una actividad que también atrae sobremanera a los criollos y en la que los mestizos están subrepresentados), y la presencia de cinco mulatos entre los sastres, otra actividad que suele adscribirse a la "capa superior" de los artesanos. ${ }^{33}$

Queda entonces como un hecho a

33 No hemos agregado en este cuadro a los sirvientes (nueve individuos) y criados (24) porque en éstos, al revés de lo que ocurre con los restantes datos de ese cuadro, si están representados los indigenas y las mujeres, y entonces falseariamos las conclusiones que hemos hecho. destacar la alta participación de los criollos en las ocupaciones artesanales, y la existencia indudable de un abundante sector de españoles pobres en la ciudad que se ven obligados a ganarse el sustento con el trabajo de sus manos en los diversos oficios artesanales, cosa que era impensable en áreas como el río de la Plata -donde los criollos pobres podian todavía darse el lujo de no ser artesanos- pero que parece ya bastante común en el México de fines del siglo XVIII. Por supuesto, esto debe relacionarse con la relativa

Los sirvientes y criados tienen la siguiente estructura étnica y sexual:

Ind. Mest. Crio. Mul. Tot. Н. М. Н. М. Н. М. Н. М. Н. М.

Sirv. $\quad-\quad-71 \cdot 1 \cdot 27$

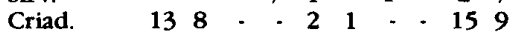


facilidad para convertirse en campesino autónomo en el área ríoplatense, pero no podemos atacar ahora este es. pinoso problema.

La gráfica 2 nos muestra datos comparativos entre la estructura ocupacional -agregando aquí las cifras sobre co. mercio, burocracia y clero que examinamos antes-y la estructura étnica de la poblacion de la villa. Es perceptible una tendencia a que sean más los criollos que las castas los que posean una ocupación según el censo. Por supuesto, el hecho de que la edad promedio de los criollos sea un poco superior a la de las "castas", ${ }^{34}$ influye también en este resultado, pero parece evidente que hay un sector flotante de población perteneciente a castas que no tiene ocupación señalada en el censo; en pocas palabras, se trata de población desocupada o parcialmente ocupada en tareas muy diversas y que no merecieron la atención del censista, probablemente por su alta inestabilidad.

Asimismo, debemos tener mucho cuidado y no tomar las calificaciones socioprofesionales del padrón en los términos que hoy en día, en una sociedad industrializada, serían considerados; el hecho de que alguien diga al censista que es herrero, tejedor $o$ arriero, no es óbice para que esa misma persona tenga diversas actividades, amén de esa que él considera la principal; y los datos precedentes, si los tomamos al pie de la letra, alejan demasiado a estos artesanos del mundo rural

34 En efecto, según los datos censales, los españoles tienen una edad promedio de 25.5 años, los mulatos de 20.5 , los mestizos de 20.6 y los castizos de 18.7 años. al que seguian inexorablemente conectados. Así por ejemplo, y tomando sólo algunos casos, Francisco Palacios, según el censo, era un lanillero castizo, casado con una india y tenía 52 años en 1791; veinte años antes, en 1772 , había hecho un testamento, en ese entonces estaba casado con una tal María Dolores, mestiza; tenía tres telares, pero además poseía varios pedazos de tierra en Tepeaca, arrendaba tres solares con magueyes y maíz, y poseía un toro y un caballo. El testamento nos muestra una situación ocupacional mucho más compleja que la que presenta el censo y este Francisco Palacios es mucho más un pequeñísimo productor rural que un simple tejedor de lanillas. ${ }^{35}$ Otro tanto ocurre con Miguel Sánchez, criollo, tejedor y casado con criolla, con un hijo de 12 años también tejedor, según el censo; en 1802, en ocasión de su testamento, comprobamos que sus bienes rurales, además de dos telares, eran un solar con magueyes comprado a don Francisco Tamayo, un conspicuo hacendado local, dos bueyes y un caballo ensillado. ${ }^{36}$

Y esto no ocurre sólo con los tejedores -de lejos la ocupación dominante en la pequeña villa-, pues hemos hallado también ejemplos de arrieros o de herreros cuyas actividades resultan al. go más complejas que la mera enunciación de esa ocupación principal, o cambian pasando de un oficio a otro en algunos casos. ${ }^{37}$

¿Es Tepeaca un caso excepcional,

35 AGNP, Tepeaca, 1772, f. 50.

36 AGNP, Tepeaca, 1802 , fs. 8991 vta.

37 José Muñoz, un criollo que es arriero con mulas según el censo de 1791 , y que casado con 


\section{SECUENCIA}

Gráfica 2. Tepeaca, 1791. Estructura socioétnica y ocupaciones

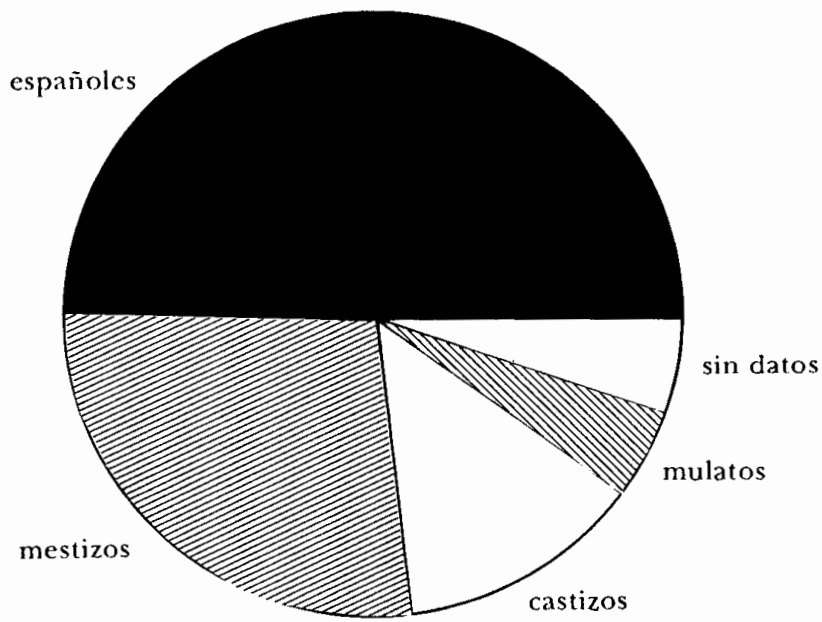

total pob. masculina

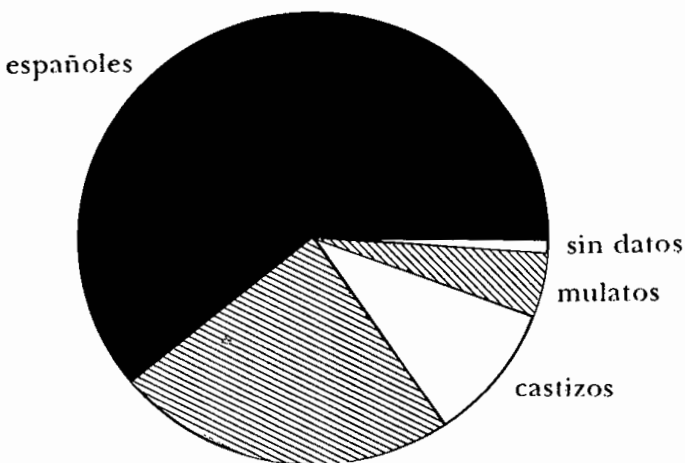

mestizos

varones con ocupación 


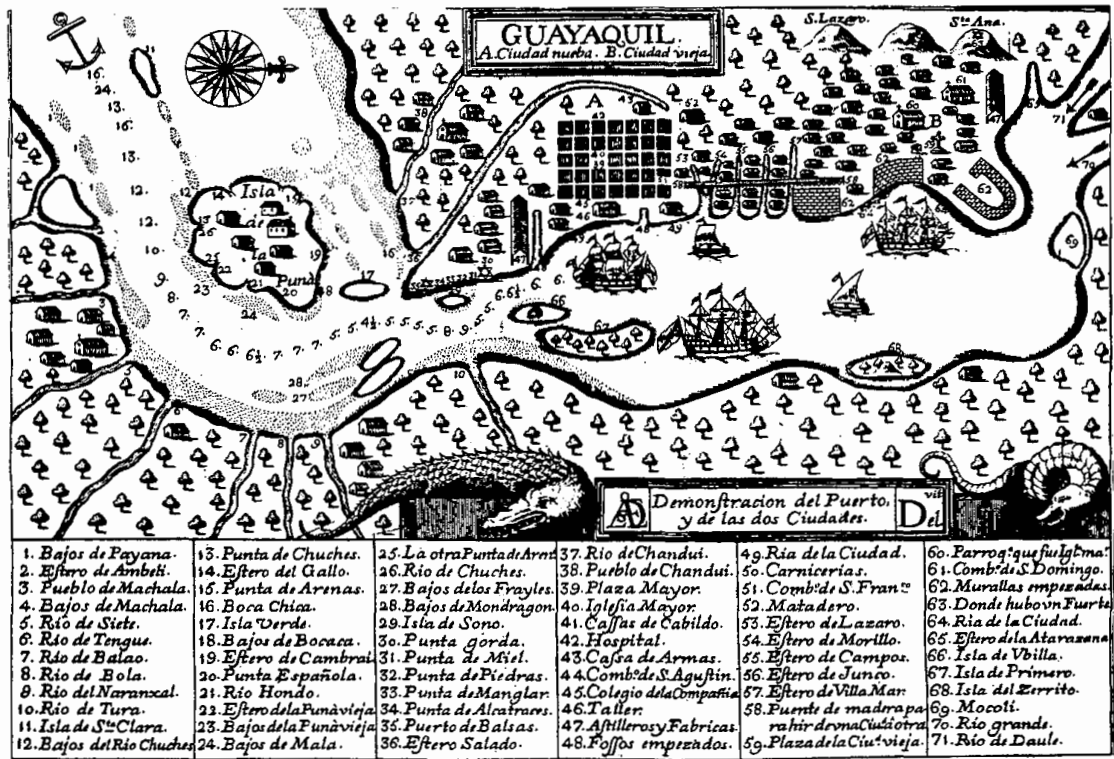

en el contexto urbano de Nueva España a fines del siglo XVIII, con respecto a

una criolla tienen dos hijos, uno de los cuales también es arriero. Según el testamento de 1795, tiene varias casas y solares poblados con magueyes (AGNM, Tepeaca, 1795, s/f); Mariano Vega, según el censo, es un herrero español casado con una mestiza; en la misma casa habita la suegra en condición castiza y un sobrino de 13 años, también español y herrero. En el testamento del año siguiente se autodenomina "don" Mariano de la Vega y afirma poseer, además de las herramien. tas de la herrería, un caballo ensillado, armas y un solar arrendado con 300 magueyes (AGNM, Tepeaca, 1792, f. 64). Miguel Bravo es, según el censo, un arriero castizo casado con una criolla; posee una hija de 13 años y un huérfano de un año; vive en la misma casa. En 1818 , en su testamento, Bravo aparece como castizo y viudo, pero ahora es tejedor y posee varios solares con magueyes, uno de los cuales está en el barrio indio de Ocotlán (AGNMP, Tepeaca, 1818, s/f) los niveles detectados de correlación entre etnia y ocupación? Las conclusiones de algunos trabajos basados en los mismos padrones de Revillagigedo no son coincidentes, y esa falta de coincidencia depende más, en casi todos los casos, del punto de vista del observador que de los datos presentados por los censos.

En el caso de la ciudad minera de Guanajuato, David Brading ha demostrado que allí también los criollos "cruzaban toda la escala de trabajos, desde los de abogado o sacerdote, hasta los de trabajadores de las minas y arriero."38 Pero si la minoría de ellos (784 indivi-

38 Brading, "Grupos", 1972, p. 465. 
duos) se hallaban integrados a la elite local, unos 3000 criollos compartían las mismas actividades artesanales, mineras y de servicios en las que se concentraban los mestizos y mulatos: cerca del $49 \%$ de los criollos "verdaderamente proletarios" eran trabajadores mineros, y en dos ocupaciones de evidente "bajo estatus" como las de sirvientes y carboneros, los criollos no sólo estaban superrepresentados, sino que en términos absolutos sobrepasaban tanto a los mestizos como a los mulatos. Sin embargo, también es cier. to que, entre los trabajadores de la minería, el sector más importante era el de los mulatos: pero al lado de los 1881 mineros mulatos (que representaban $60 \%$ de la respectiva población masculina adulta), había 1328 criollos y 1378 mestizos que compartían las mismas condiciones de trabajo. ¿Estas cifras significan -como se pregunta el mismo autor- que en este sector de la población de Guanajuato, "las categorías étnicas fueron apenas algo más que etiquetas arbitrarias, inercias sin sentido del pasado"? Para responder esta última pregunta, Brading analiza, como prueba de la homogeneidad de los grupos, la elección matrimonial de los trabajadores de las minas: en general los españoles se casaban con mestizas, los mulatos con indígenas y los mestizos con españolas o indígenas.

Su conclusión es que "los mulatos y los indigenas formaban un grupo separado inferior, con el cual, el grupo hispano-mestizo no buscaba el matrimonio a pesar de la proximidad social entre ambos"; por lo tanto, para Brading "las distinciones raciales, aunque no indican por sí mismas distinciones de clase, en parte definieron el estatus individual en la estimación de los compañeros [...] La conciencia racial permanecía aún fuerte, y así dentro de cualquier empleo, las personas de diversas razas gozaban de distinto estatus".

Pero si bien en los sectores bajos habría cierta "segregación racial" con respecto a mulatos $\mathrm{e}$ indios por parte de criollos y mestizos, por otro lado los mismos datos que presenta este autor y su argumentación nos hablan de una integración -en esos sectores- de crio. llos y mestizos, dado que él sostiene que el proletariado español y el mestizo en realidad formaban una sola comunidad; esa integración diluye bastante la rigidez de las diferencias étnicas, al menos en ese nivel.

En su estudio sobre Querétaro, Celia $\mathrm{Wu}^{39}$ sostiene que la participación de los criollos en la elite y su predominio en el nivel de los artesanos calificados, conjuntamente con la segregación espacial, serían indicadores de una sociedad organizada más en líneas de castas que en clases económicas.

En una realidad geográficamente más próxima a Tepeaca, la de la villa de Atlixco, con una población de 3367 individuos registrados por el padrón de 1791 aunque, a diferencia de Tepeaca, con una fuerte presencia de población de color (los pardos constituyen $25 \%$ del total), el análisis realizado por Agustín Grajales tiende a poner de relieve una sociedad donde el estatus social estaría íntimamente relacionado con la categoría étnica de manera aún

$39 \mathrm{Wu}$, "Population", 1984. 
más marcada que en Guanajuato. Al igual que en esa ciudad, los europeos y los pardos señalan los límites de la jerarquía en el trabajo; pero aquí el espanol criollo estaría sobrerrepresentado -en relación con las expectativas- en las tres primeras categorías en las que se clasificó a la población masculina activa según el estatus (elite, "cuadros de mando y ocupaciones generosas" y "ocupaciones artísticas y servicios intermedios"), en tanto que "a medida que desciende la escala se resiste a aparecer, desdeñando la servidumbre y el artesanado" ${ }^{40}$

Una lectura distinta de las mismas cifras proporcionadas por Grajales permitiría subrayar el hecho de que menos del $15 \%$ de los criollos pertene. cía a la elite, en tanto que $42 \%$ de los mismos se repartían entre las diversas ocupaciones que correspondian al artesanado no calificado, arrieros y otras actividades de bajo estatus donde se concentraban los mestizos y pardos.

Esta misma doble lectura ha dado lugar a la polémica que mencionamos al inicio de estas páginas en torno al análisis efectuado por Chance y Taylor sobre la realidad social de la ciudad de Oaxaca. Si aplicáramos el mismo esquema con el que el autor analiza las cifras del censo de Atlixco, pondríamos de relieve que los criolios (que constitúan $48.6 \%$ de la población masculina no indígena de la ciudad) se hallaban sobrerrepresentados en el sec. tor de los "artesanos de clase alta", ya que eran $71.8 \%$ de los mismos, en tanto

${ }^{40}$ Grajales, "Estructura", 1989. que los mestizos y castizos (con $26.6 \%$ de la población masculina) apenas conformaban el $17.3 \%$ de esa capa del artesanado. ${ }^{41}$ Pero siguiendo la propia lectura del autor -y más acorde con el objetivo de nuestro trabajo-, interesa señalar que, en la Oaxaca de fines del siglo XviI, sólo $8 \%$ de los criollos formaban parte de la elite, y que $53 \%$ de los hombres adultos de esa condición desempeñaban alguna de las diversas actividades agrupadas por Chance en el rubro "Artesanado de baja clase $y$ arrieros", un sector de la estructura socio-ocupacional donde esos 816 criollos se integraban con 702 mestizos y castizos (que conformaban $84 \%$ de este grupo étnico) y 536 mulatos (cerca del $\mathbf{8 8} \%$ del total de los hombres adultos de esta condición registrados con ocupación).

Volviendo ahora a nuestro caso de estudio, ya hemos visto anteriormente que no hay una sustancial diferencia en cuanto a las ocupaciones de criollos y "castas", pero también cabe preguntarse si en la villa de Tepeaca hubo diferencias en los patrones residenciales y habitacionales como habría sido el caso de Querétaro, o bien si encontra. mos una realidad semejante a la de la ciudad de Oaxaca donde, si se dejan de lado las pocas manzanas próximas al zócalo $\mathrm{y}$, obviamente, los barrios indios, el resto del espacio urbano se caracterizó por una ocupación "ra. cialmente mezclada". ${ }^{42}$

41 Chance, "Razas", 1982, p. 204.

42 Chance, "Ecology", 1981. 
UN INTENTO DE MEDICION DEL FENOMENO EN EL TIEMPO: LOS MATRIMONIOS ENTRE DIVERSOS SECTORES SOCIOETNICOS

La marcha del proceso de mestizaje en Tepeaca puede ser seguida a través de una serie de indicadores. Por ejemplo, en $1743,61 \%$ de las familias eran indígenas en toda la jurisdicción de la parroquia, constituyendo los criollos el $23 \%$ de las familias y el restante $16 \%$ correspondia a las "castas"; en 1777 , los porcentajes de familias indigenas llegan apenas a $51 \%$, siendo $24 \%$ familias de criollos y $24 \%$ de "castas" 43 (el cálculo de "familias" para 1777, parte de la base de la aplicación del factor 3.82 , que tomamos de Cook y Borah). El crecimiento del mestizaje también puede ser seguido a partir de los porcentajes de bautismos realizados por los curas en la parroquia: en la década 1730-1739 tenemos $80.8 \%$ de bautismos indígenas y en la década 1770 1779 ese porcentaje es $68 \%$ del total.

Pero pasemos ahora a un aspecto de la cuestión que puede contribuir a comprender mejor el papel de la vida "urbana" como ámbito ideal para los contactos socioétnicos y las relaciones matrimoniales entre los diversos grupos. Desde luego que somos conscien. tes de la desigual percepción del fenómeno, pues aquí estamos hablando fundamentalmente de las uniones legales -aun cuando los censos y padrones muestran probablemente algunas de

43 AGI-México, 2578, "Informe del alcalde mayor de Tepeaca" (1743), y padrón de la parroquia de Tepeaca, 1777, en tbid. las uniones de hecho también- y es obvio, como ocurre en otras partes, que las uniones de hecho deben haber tenido también un papel importante en este proceso. Trabajaremos con los censos, los padrones militares, los padrones de tributarios y los archivos pa. rroquiales. ${ }^{44}$

Hemos realizado una serie de gráficas que permitirán rediscutir algunos de los criterios de interpretación que hemos expuesto en la primera parte de este trabajo. En la primera de ellas, la gráfica 3, se han representado los datos -referidos a porcentajes respecto de cada categoría socioétnica- tal como aparecen en los padrones de $1777 \mathrm{y}$ 1791.92.

Señalemos que estamos aquí frente a los datos de la villa de Tepeaca con sus barrios indígenas, por tanto no hay cifras para los habitantes de los pueblos y de las haciendas (en estas últimas la presencia de criollos y "castas" es importante). Si vemos los datos de 1777 comprobamos ante todo que para el padrón casi no hay castizos en ese momento - distinta es la visión de los regiștros parroquiales como se verá más adelante- $\mathrm{y}$ es por ello que hemos agregado las cifras referidas a los mulatos. Tratemos cada categoría por separado y en forma comparativa en una y otra fecha.

Los españoles (en realidad, se trata de "criollos" obviamente y no de "peninsulares") sufren entre 1777 y 1791 . 92 un proceso de mestizaje evidente a simple vista: hemos pasado de casi $80 \%$

44 AGI-México, 2578; AGNM, Padrones, 38; AGNM, Genealogia, varios rollos; Archivo Parroquial de Tepeaca, Tepeaca. 
de matrimonios endogámicos a sólo $70 \%$ en 1791-92. En los mestizos también se ve un notorio cambio: si en 1777 la preferencia parece ser mestizo/mestiza, en 1791.92 la presencia de las indias ha crecido en forma evidente como partner preferido por los varones mestizos. En los indios, si bien se percibe un débil crecimiento de presencia de las mestizas, el casamiento "endogámico" sigue siendo dominante.

¿Qué pasa si nos referimos a los datos de los registros parroquiales? ¿O sea a las cifras para la parroquia entera, incluyendo entonces a los pueblos de indios y a las haciendas? Primero observamos algo que ya ha sido señalado por otros autores, es decir, la mayor puntillosidad clasificatoria de los registros frente a los padrones (lo que obviamente, partiendo del análisis realizado en la primera parte de este trabajo, no quiere decir más que eso: "puntillosidad clasificatoria", y no significa que este registro refleje mejor una supuesta realidad objetiva: quién determina la pertenencia étnica, ¿el cura?, ¿los testigos?, ¿es un hecho asumido por los participantes en el acto?).

Es interesante verificar, en el sector correspondiente a los mestizos, cómo quince años más tarde y por obvias razones, las que eran sólo indias, mestizas y españolas, se han transformado en indias, castizas, mestizas y españolas. En la gráfica 4, además, podemos considerar también a los castizos y verificar que no presentan cambios radicales en la elección de su partner entre las dos fechas.

Pasemos ahora a las gráficas 5 y 6 que "mezclan" los dos tipos de fuentes pero para el mismo periodo, y recordemos una vez más que en ellos se combinan dos tipos de fuentes y dos ámbitos: la ciudad para los padrones y la entera parroquia para los registros eclesiásticos. En los años 1772-1778 es notable la mayor presencia de esposas indias que expresan los registros parroquiales en las categorías de "españoles" y mestizos -se trata probablemente de las familias multiétnicas de las haciendas - aunque se mantiene el porcentaje de miscegenación del grupo "español". En cambio, los datos de los años 1786-1792 acentúan aún más el fenómeno señalado de la indudable preferencia por esposas indias en el casco urbano de la ciudad (especialmente para mestizos y castizos) y la mayor presencia de las castizas en los matrimonios de españoles y mestizos (y obviamente de los mismos castizos) en el ámbito de toda la parroquia.

¿Qué pasaría si examináramos los datos de los registros parroquiales pero exclusivamente para el ámbito "urbano", es decir, el casco estricto de la villa, dejando fuera del análisis tanto a los barrios como a los pueblos de indios y las haciendas? Hemos hecho dos gráficas (7 y 8) en las que aparecen las preferencias de mujeres y hombres en ese ámbito.

En el periodo 1770-1779 los niveles de mestizaje de españolas y españoles son algo diferentes -las mujeres parecen cruzar más facilmente las líneas de separación socioétnica-, pero en realidad si lo comparamos con los registros para la entera jurisdicción parroquial, los porcentajes, si bien son ligeramente superiores, son muy similares. Eso no debería extrañarnos, pues el peso 


\section{SECUENCIG}
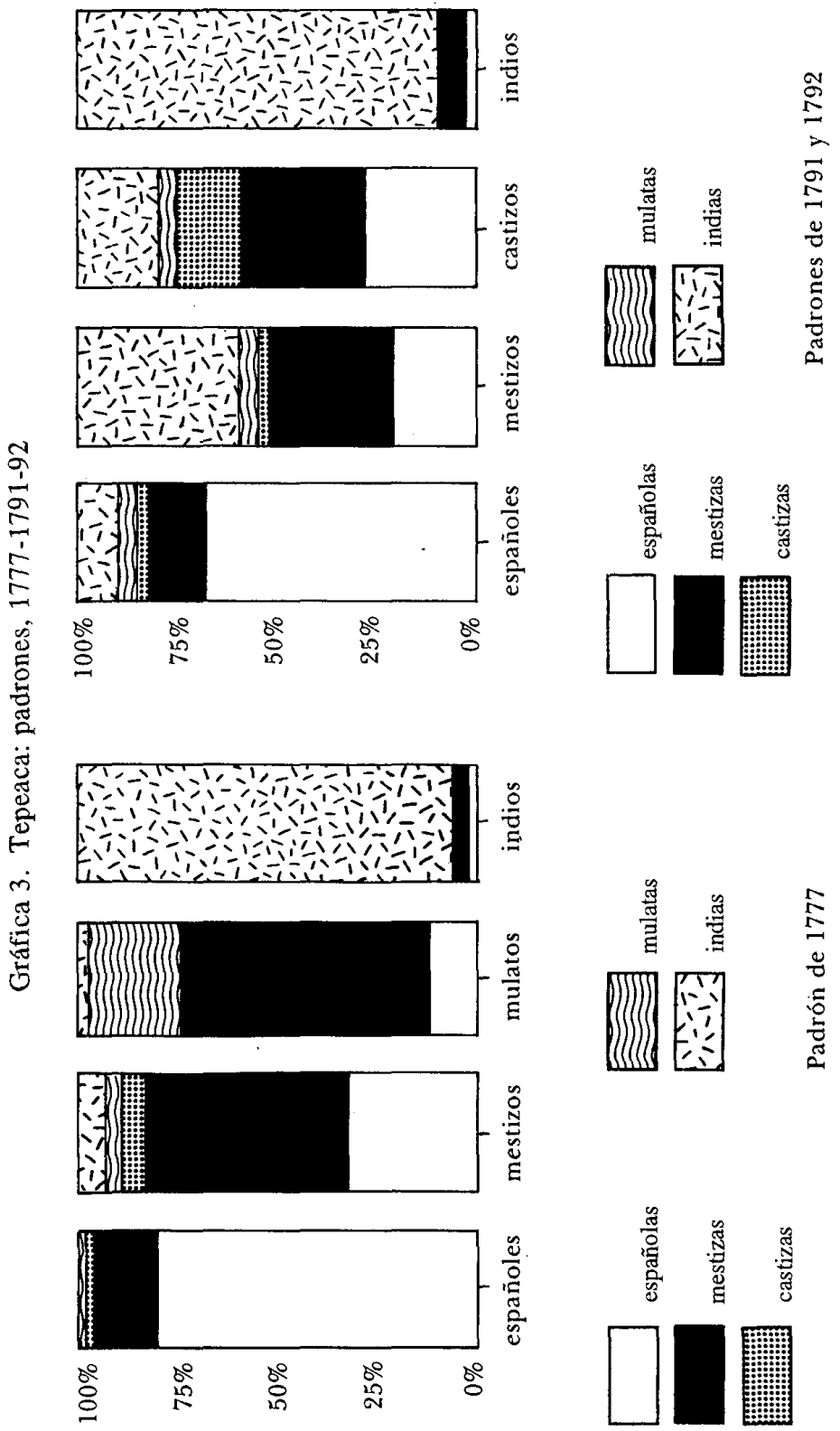


\section{SECUENCIA}
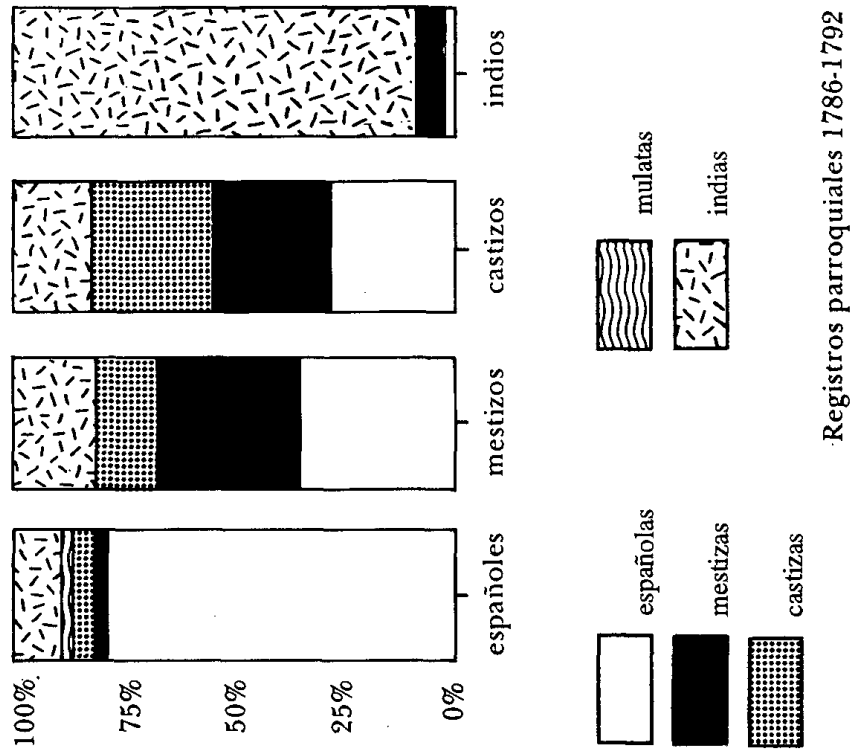

I

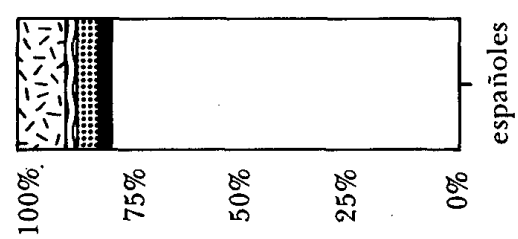

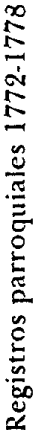
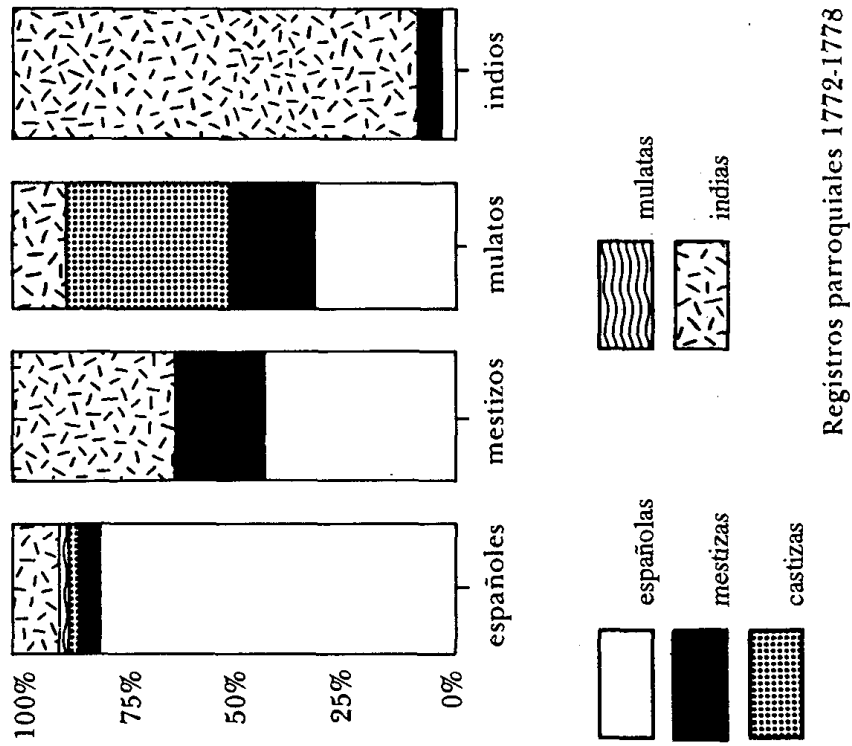


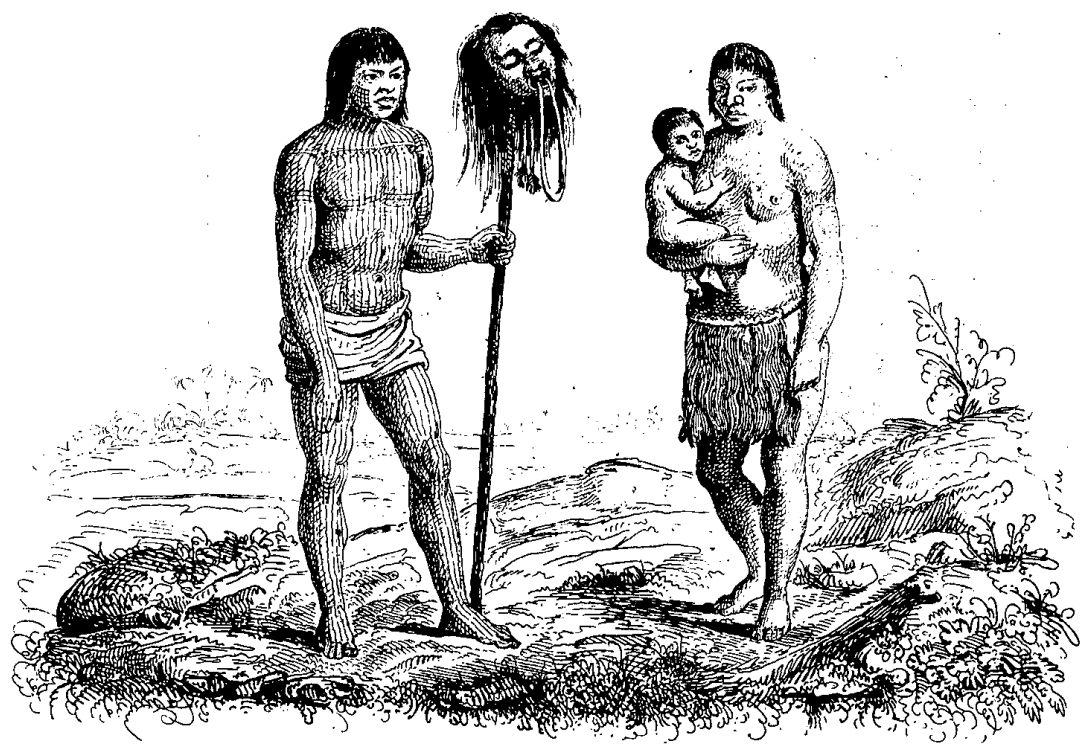

de los criollos viviendo en el casco es tan grande, que su comportamiento expresa casi el comportamiento de to. do el grupo en la entera parroquia. Más interesante es ver qué pasa con "castas" $\mathrm{e}$ indios. En este caso observamos que mestizos y mestizas parecen ocupar un lugar importante como partner privilegiado junto a los criollos. El comportamiento de los mestizos, por razones idénticas a la situación de los criollos que hemos mencionado, se asemeja al de toda la jurisdicción, pero indias e indios aparecen ligados a partners radicalmente diversos a los de sus pares que viven en barrios, pueblos y haciendas.

Con algunas diferencias -se invierten aquí los grados de receptividad a la apertura entre hombres y mujeres criollas- el periodo 1790-1799 muestra situaciones bastante similares. Para indias e indios, una vez más se verifica la importancia del ámbito "urbano" como elemento de miscegenación socioétnica.

Finalmente, las gráficas 9 y 10 nos muestran ahora, sólo para los novios varones, la relación entre el "casco urbano" y la entera jurisdicción de la parroquia. Siempre que hablamos del "casco", la presencia de mestizas y de criollas como partners es notable -en relación a los datós de la parroquiapara todas las categorías. Es interesante además verificar que los participantes en estas uniones represëntan porcentajes muy cercanos a los que hemos calculado (según los datos del cuadro 1) para la población total -sin los ba- 


\section{Cuadro 4. Estructuras familiares en Tepeaca, 1791}

\begin{tabular}{|c|c|c|c|c|}
\hline & Número & Individuos & Ratio & Porcentaje \\
\hline Familias nucleares & $\because 242$ & 1015 & 4.2 & 56.4 \\
\hline Familias extendidas & $\therefore \quad 140$ & 784 & $\begin{array}{c}5.6 \\
- \\
7\end{array}$ & 43.6 \\
\hline \multicolumn{3}{|c|}{$\begin{array}{l}\text { os indígenas- del casco de la villa en } \\
91,45 \text { por tanto, si bien se trata sólo } \\
\text { las uniones sancionadas por la Igle- }\end{array}$} & $\begin{array}{l}\text { CIUDA } \\
\text { ESTRUC }\end{array}$ & $\begin{array}{l}\text { PATRONES DE } \\
\text { RAS FAMILARES }\end{array}$ \\
\hline
\end{tabular}
de las uniones sancionadas por la Iglesia, su representatividad es alta en relación con los totales de cada grupo.

¿Cuáles serían entoncés las conclusiones de este acápite en función de nuestros intereses en el marco de este estudio? Pensamos que lo más rèlevan. te es la acentuación del carácter del ámbito "urbano" como espacio ideal para los encuentros entre grupos socioétnicamente diversos. Pasemos ahora a un examen más detenido de ese ámbito. ${ }^{46}$

45 En efecto, sobre un total de 374 novios, tenemos $50 \%$ de novios criollos, $23 \%$ de mestizos, $20 \%$ de novios indígenas, $6 \%$ de castizos y $2 \%$ de novios pardos y mulatos en el entero periodo 1780-1799 (hemos preferido hacer el cálculo sobre un periodo lo suficientemente amplio como para que los números tengan una relevancia estadistica significativa).

46 En un trabajo reciente sobre el proceso de mestizaje en la parroquia urbana de San Pedro, perteneciente a la ciudad de Choiula (Puebla), y basado en el análisis de las informaciones matrimoniales del periodo $1754-1790$, la autora ha podido detectar cómo a partir de una tendencia inicial hacia la endogamia las uniones mixtas fueron adquiriendo mayor importancia, "siendo

¿Cómo vivía la gente en la ciudad? ¿Vivía en familias nucleares o en familias complejas o extendidas? ${ }^{47}$ ¿Vivía en casas aisladas o en casas que reunían a varias familias? Comencemos por el primero de los dos problemas:

Parece que estuviéramos ante una realidad de una estructura familiar predominantemente nuclear y aislada.

ocasionalmente más de la mitad del total de los enlaces pretendidos"; empero, hacia fines del siglo x'in', củando el'curato se transformó en un asentamiento mayoritariamente mestizo, "se reforzó nuevamente la téndencia al matrimonio al interior del grupo sóctótracial". Al igual que en Tepeaca, o en otras, fealidades novohispanas, en todo el periodo analizado la endogamia alcanzó porcentajes alțos en los grupos español (79\%) e indígena (83.1\%); pero relativamente bajo para los mestizos (64.6\%), eñ rántó que la exogamia fue la norma para los mulatos y pardos. Castillo, "Mestizaje", s.a.

47 Llamamós aquì "familia nuclear" a la compuesta por los cónyuges - o el cónyuge supérstitey sus hijos; por lo tanto, todas las otrás combina. ciones parentales ascendentes/descendentes o colaterales, las hemos englobado bajo el nombre de "familias extendidas" o "familias complejas". 


\section{SECUENCIG}
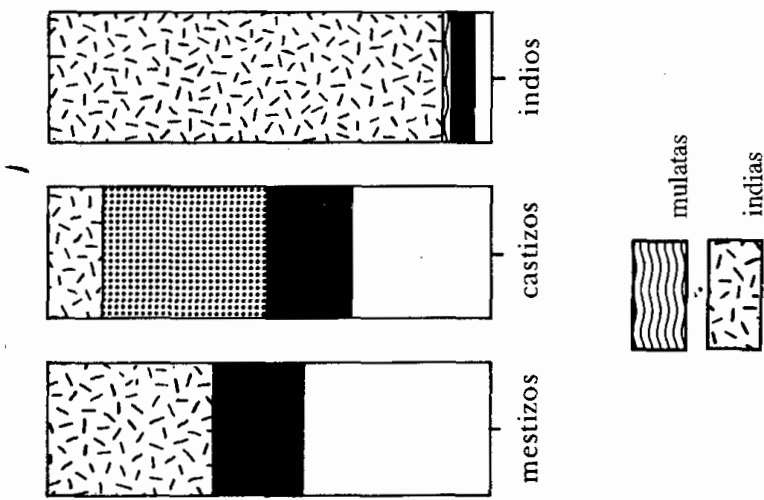

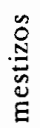

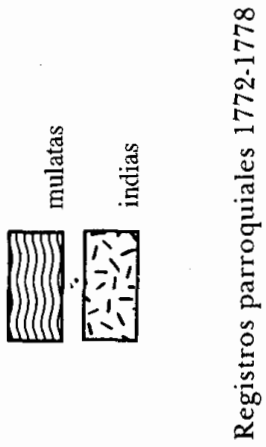

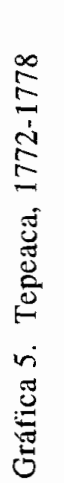

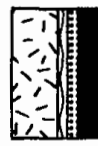

$\frac{\mathscr{s}}{\stackrel{\Xi}{0}}$
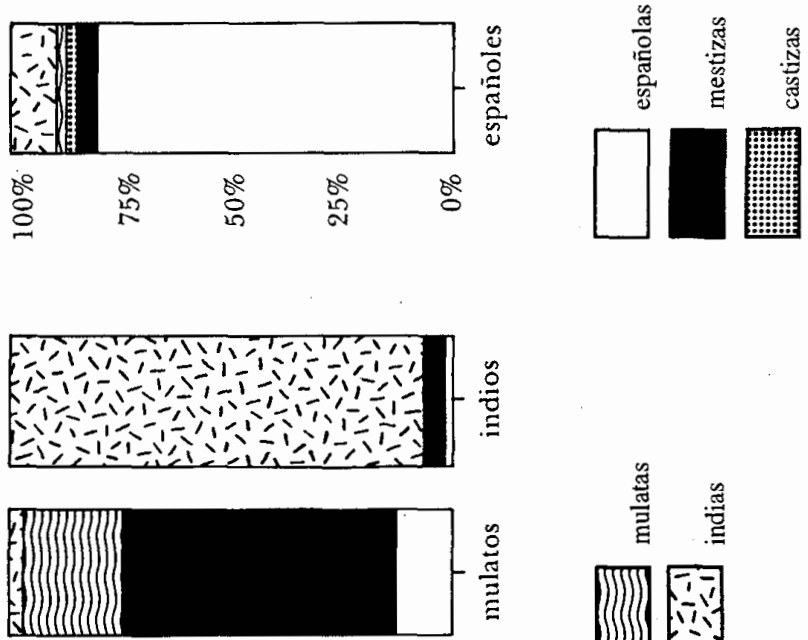

总 昜
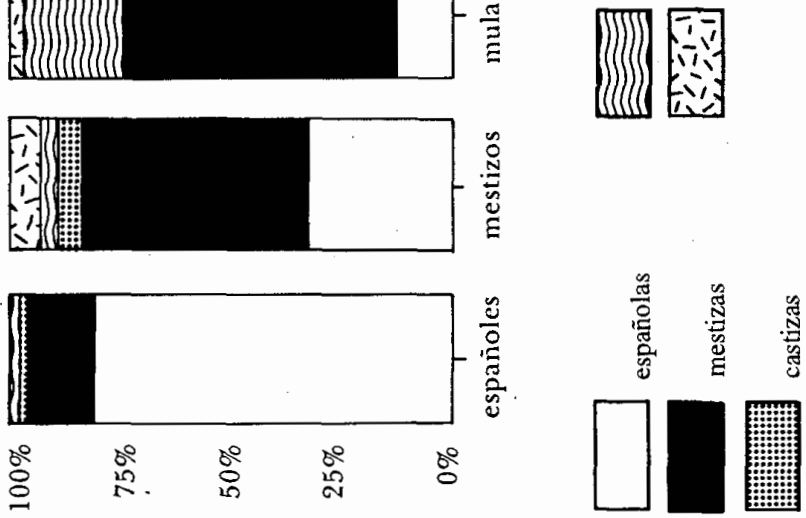


\section{SECUENCIG}
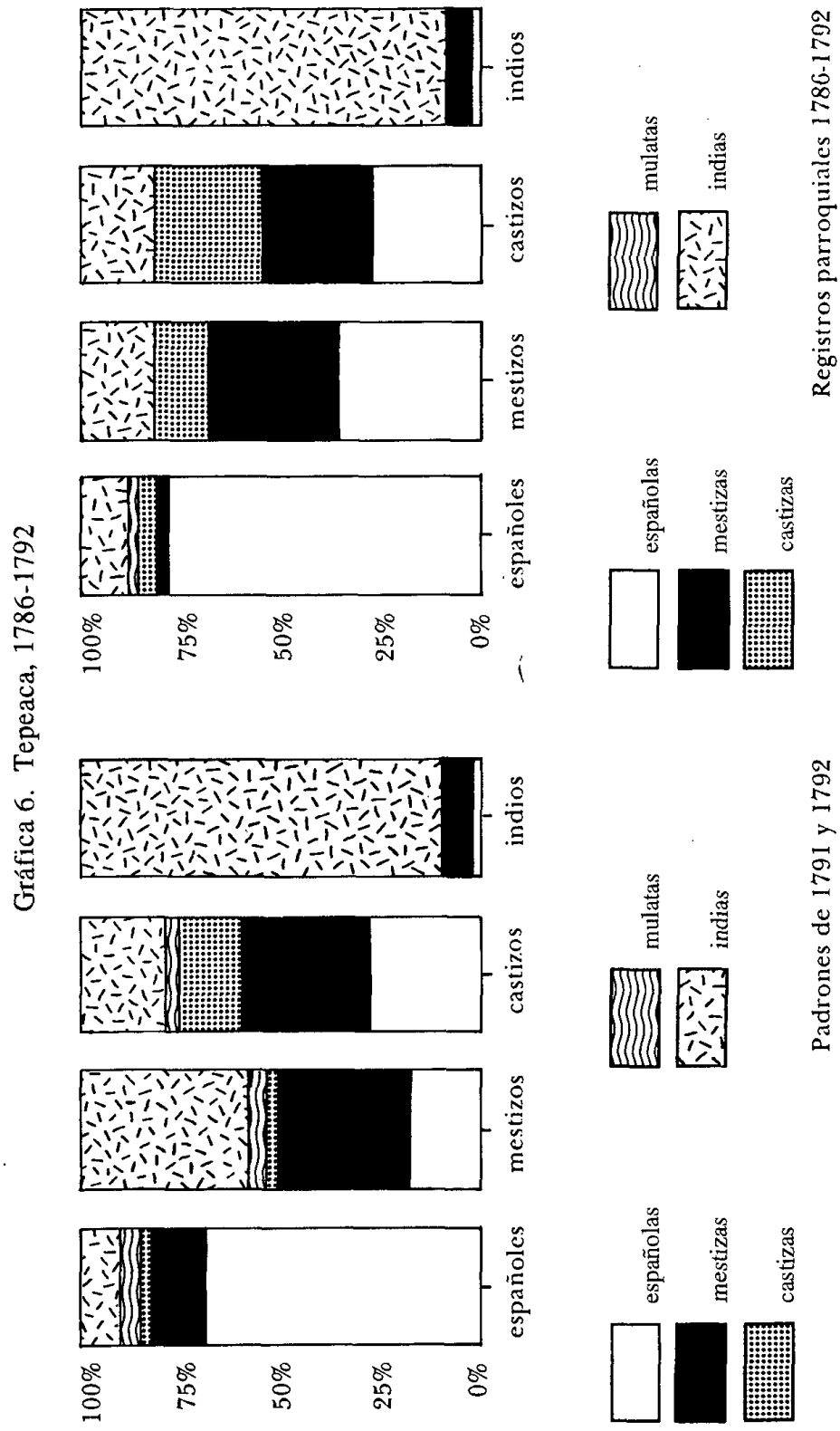


\section{SECUENCIG}

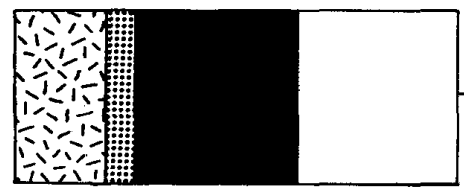

I
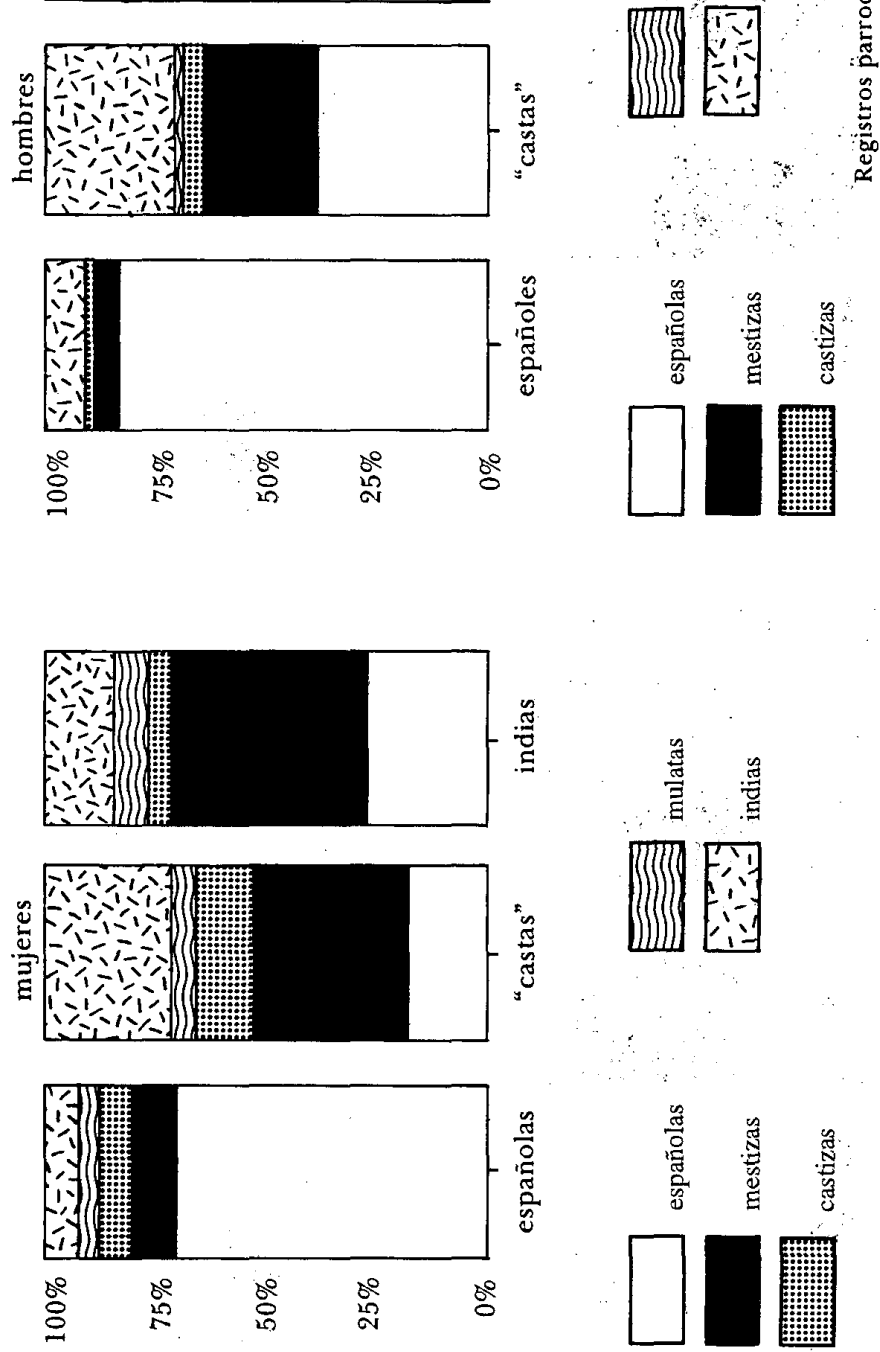


\section{SECUENCIA}
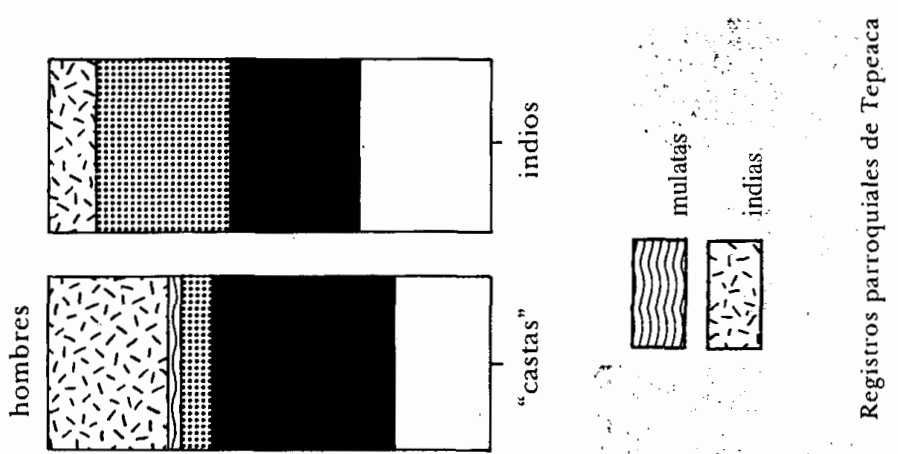

ई̊
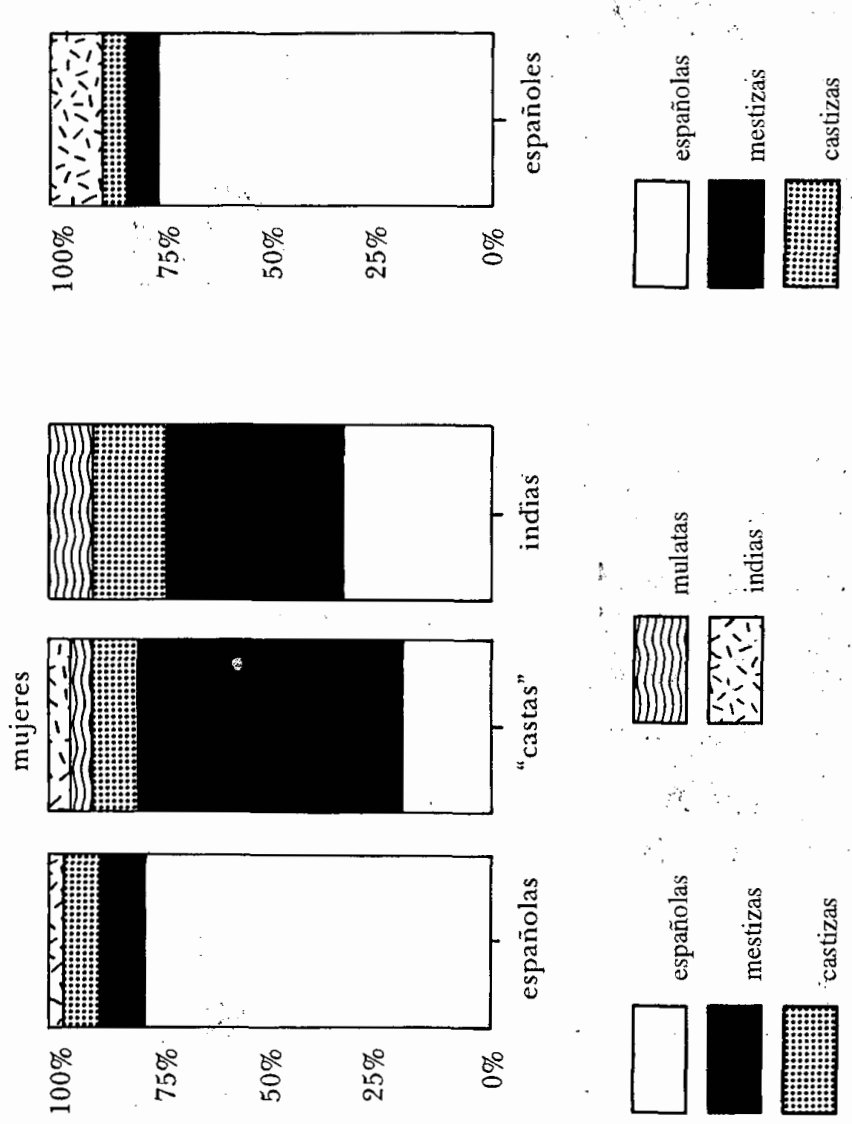


\section{SECUENCIG}
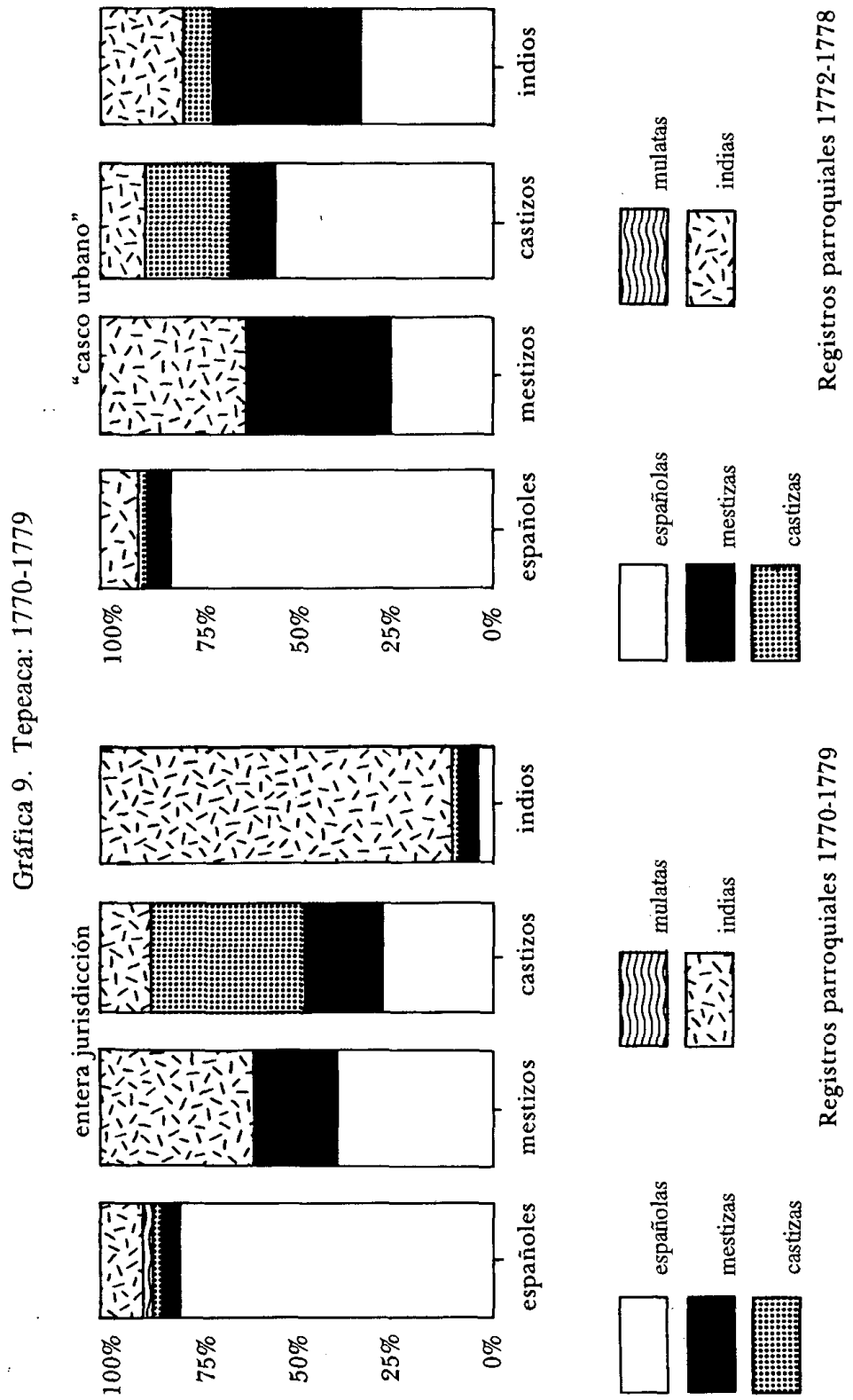


\section{SECUENCIG}
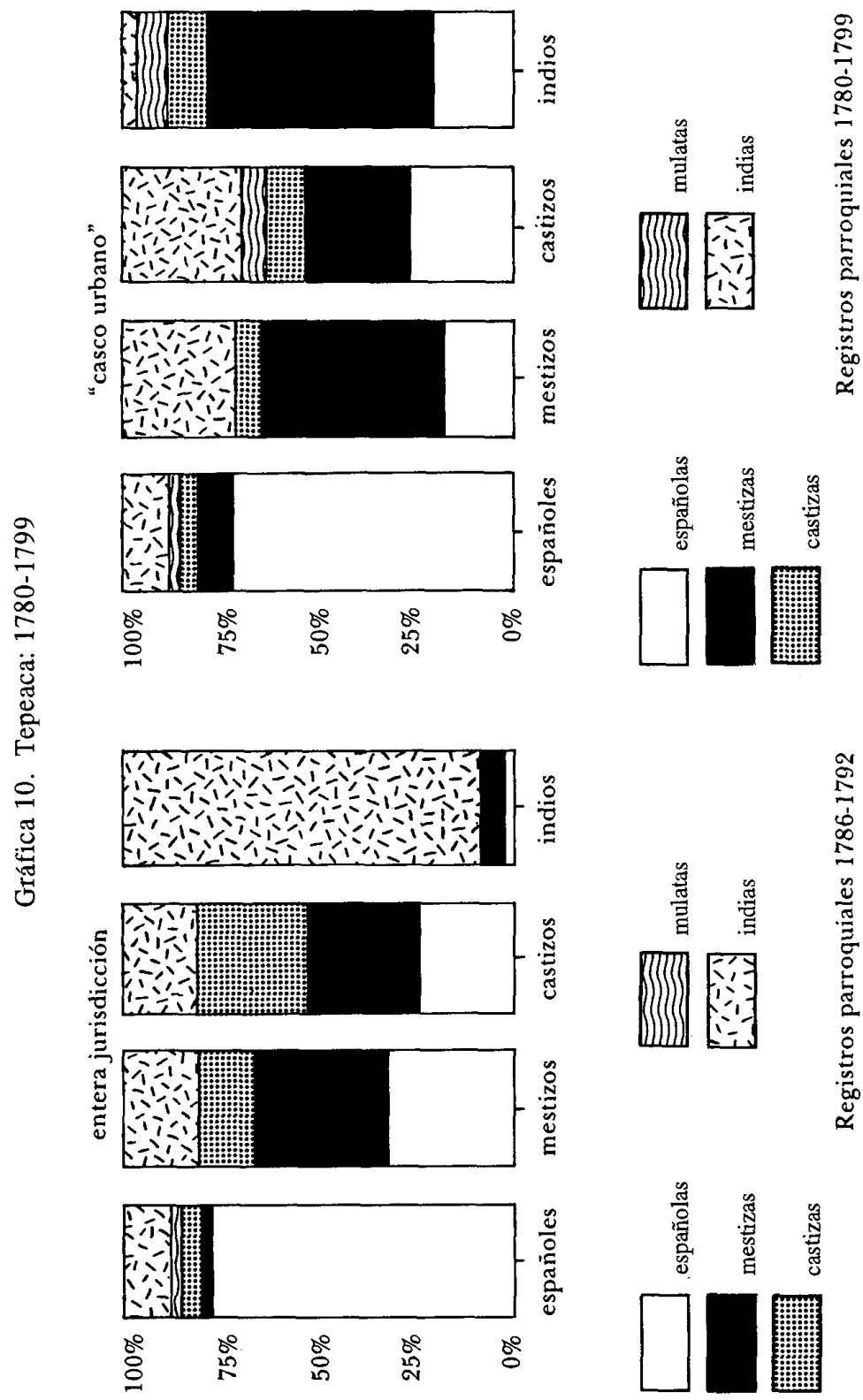
Gráfica 11. Calle Segunda de Acatzingo
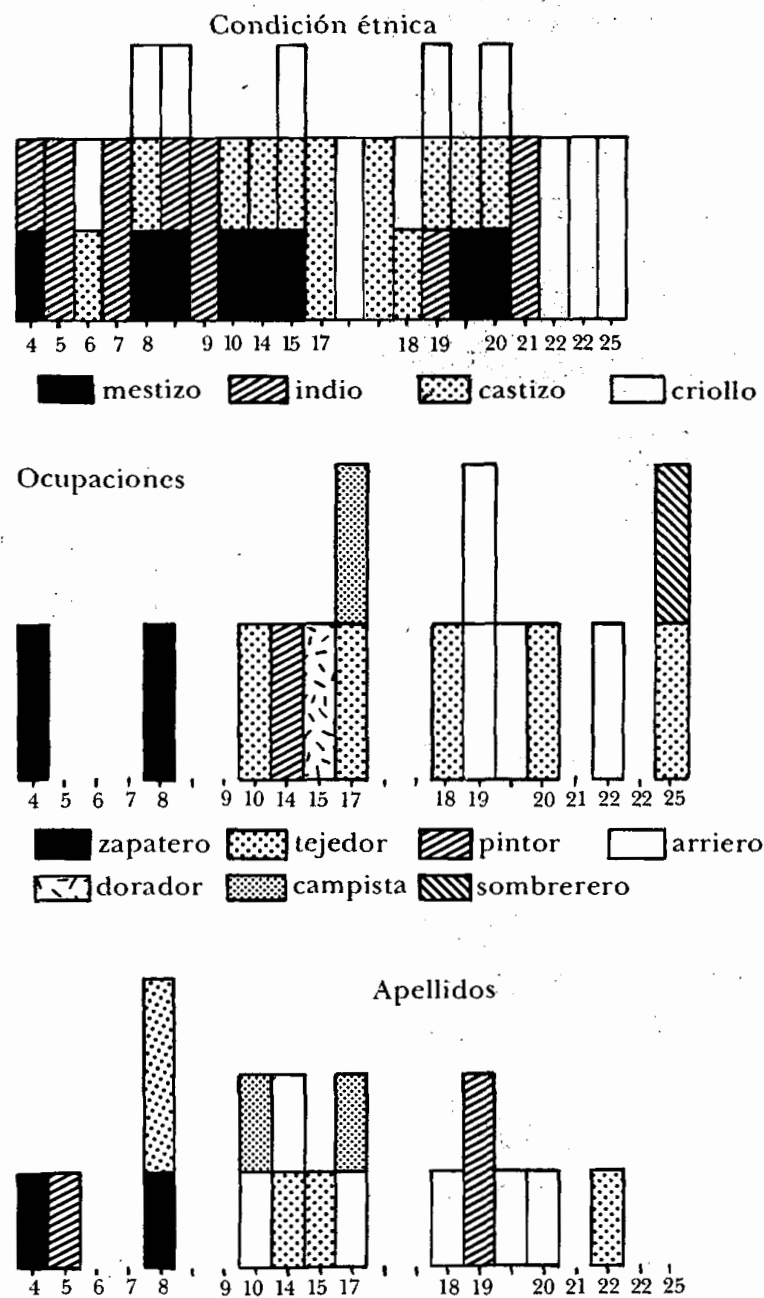

Galindo Sánchez Pantoja $\square$ Palacios \%alcón

[los números de las abcisas son los de las casas] 
Cuadro 5. Estructuras familiares y habitacionales en Tepeaca, 1791

\begin{tabular}{|c|c|c|c|c|}
\hline & Nümero & Personas & Ratio & $\begin{array}{c}\text { Porcentaje } \\
\text { total }\end{array}$ \\
\hline Casas multifamiliares & .72 & $759:$ & 10.5 & 42.2 \\
\hline $\begin{array}{l}\text { Casas unifamiliares } \\
\text { con familias complejas }\end{array}$ & 84 & 499 & 5.9 & 27.7 \\
\hline $\begin{array}{l}\text { Casas unifamiliares } \\
\text { con familias nucleares }\end{array}$ & 127 & 528 & 4.2 & 29.3 \\
\hline
\end{tabular}

Pero el cuadro 4, en realidad, es doblemente engañoso. Ante todo porque la existencia; dentro de las familias complejas, de numerosos casos con "sirvientes indios", en los cuales nuestra fuente no especifica la cantidad exacta de personas que comprende esa frase casi ritual, hace que la suma total de 784 sea la mínima posible (tomando a sólo dos individuos por cada vez que se menciona dicha frase) y entonces, por un lado, el ratio debe ser mucho mayor en la realidad y, por el otro, el porcentaje sobre el total de la población debe. ría ser un poco mayor. Y sobre todo, no todas las familias nucleares viven en casas aisladas, es decir, el fenómeno de la multifamiliaridad dentro de un mismo espacio habitacional es muy importante, como se advierte en la lectura del cuadro 5.

A hora las cosas tienen un color totalmente distinto. Vemos que la mayor parte de la población de la ciudad vive en casas multifamiliares, $y$ que un porcentaje relevante del resto tiene estructuras familiares complejas, $y$ que- da un $30 \%$ para las familias nucleares que viven en casas aisladas (lo que no obsta para que hallemos con cierta frecuencia el fenómeno del -probableparentesco entre familias de la misma calle que residen en casas distintas pero muy próximas físicamente). Además, $20 \%$ del total de las casas multifamiliares alberga en su seno a familias multiétnicas. Por otra parte, en las restantes categorías es constante la ubicación contigua de casas que podríamos llamar "monoétnicas" con las multiétnicas. ${ }^{48}$

Como es harto dificil dar cuenta al lector de la complejidad de este problema sin conocer exactamente cómo presenta la fuente los datos, vamos a dar en las páginas siguientes algunos ejemplos acerca de los diversos patrones resi-

48 Desde luego habria que hacer un mapa en el que se pudiese diseñar gráficamente este aspecto. Como el lector imaginará, hay calles salpicadas, para decirlo de algún modo, pero por supuesto las hay más "criollas" y más "indigenas". Hemos graficado una calle en el ejemplo que agregamos al texto de la Segunda Calle de Acatzingo. 
denciales y de las formas en que se manifiesta la multietnicidad en el caso que estamos estudiando. También mostraremos de qué modo estos sistemas de representación se relacionan con los vínculos de parentesco y con las ocupaciones de los cabezas de familia.

\section{Casa número 30 de la Plaza Mayor}

Se trata de una casa - que había sido anteriormente el cuartel de Dragones- donde viven dos grupos familiares compuestos de varias familias nucleares. En total conviven 22 personas en esa casa. El primer grupo familiar, el de los Gazca/Espíndola, Gazca/Huerta y Bravo/Huerta, está compuesto de diez personas en tres familias, todos criollos; hay tres herreros y un tejedor en el grupo. El "patriarca" de la casa podría ser Felipe Gazca, aun cuando una persona que debía ser probablemente su suegra (Ignacia Espíndola), de 48 años, también vive en la misma parte de la casa. Los dos restantes cabezas de familia son Santiago Gazca (לhermano de Felipe?) y Mariano Bravo, casado con una Huerta al igual que Santiago.

El segundo grupo, el de los Palacios (viuda de un Martínez), Gómez/Centeno y Gómez/Martínez está compuesto de doce personas, que integran tres familias emparentadas; de ese total de personas, ocho son criollos, dos son mestizos y dos son castizos; todos los cabezas de familia son tejedores. Es in-

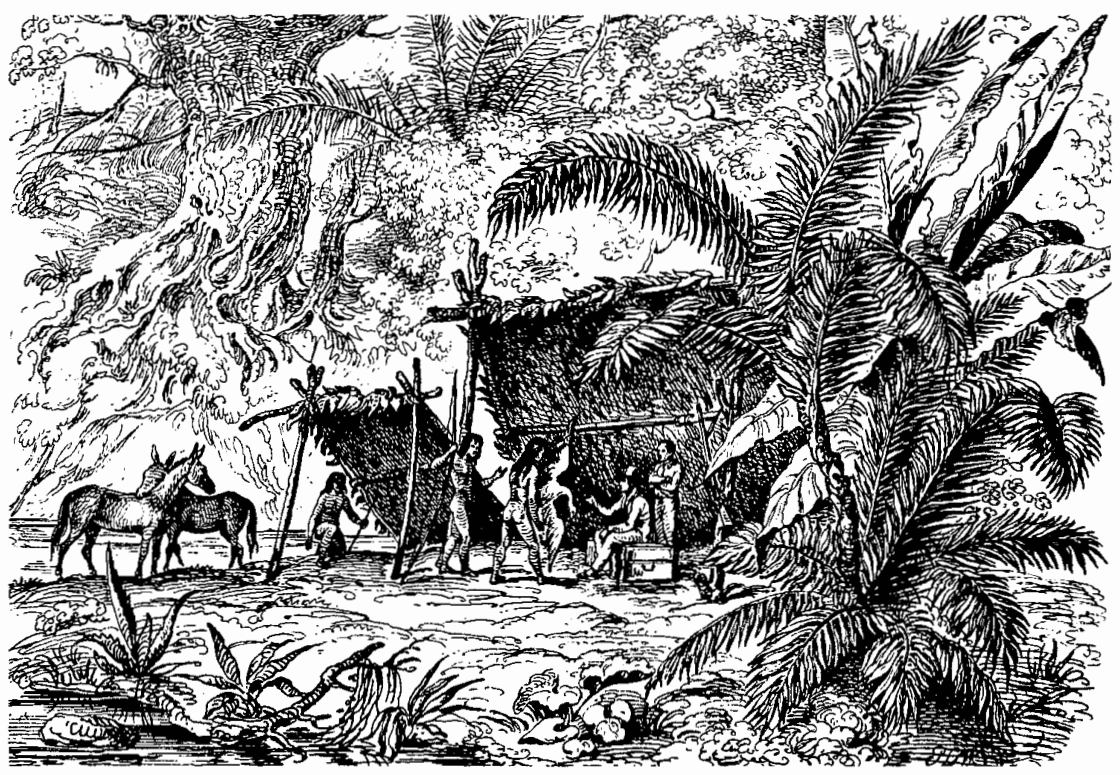


teresante señalar que una de las familias es auténticamente una familia multiétnica: Jose Ventura Gómez, tejedor criollo, está casado con una mestiza, Burana Centeno, y sus dos hijos son castizos. Hay también una mestiza que es sirvienta en la familia de los Gómez/Martínez.

En una palabra, tenemos en este caso un excelente ejemplo de cohabitación entre tres grupos familiares de artesanos criollos pobres, donde ha entrado una mestiza como pareja de uno de ellos. Se cuentan en total tres herreros y cuatro tejedores en los diversos grupos familiares, $y$ hay 18 criollos, dos mestizos y dos castizos conviviendo en este mismo espacio. Sólo una mestiza no tiene vínculos de parentesco con los grupos familiares, pero se trata de una joven sirvienta de doce años.

Calle Cuarta Real de N. S. de Guadalupe, casas 1 y 5

Caso muy claro de multietnicidad y multifamiliaridad. En esas dos casas contiguas viven trece personas en una y tres en la otra, relacionadas por pro. bables vínculos de parentesco. En la primera de las casas vive el herrero Miguel Camacho, criollo de 50 años, casado con María Francisca Monfil (o Bonfil), mestiza de 48 años, y con dos hijos castizos. Además hay trabajando un aprendiz de herrero de 16 años, del que no sabemos su condición étnica. También conviven con ellos la familia Brito/Reyes y una viuda; Brito es tratante y todos ellos son criollos. En la casa contigua vive un José Ignacio Camacho, también herrero, de 25 años y mestizo (no castizo como los hijos de Miguel, pero bien puede ser hijo de un matrimonio anterior de Miguel con una india), casado con Ana Martínez, criolla. Junto a ellos convive un losero de 28 años, castizo. En una palabra, tenemos nueve criollos, dos mestizos y tres castizos relacionados parentalmente y conviviendo en estas dos casas con diferentes ocupaciones, donde predominan los tres herreros.

\section{Calle Segunda de Acatzingo}

Por varias razones esta calle se destaca para nuestro tema. Hay sólo dos casas multifamiliares, pero aquí gran parte de los vecinos de la calle están emparentados. En realidad, de las 16 familias cuyos apellidos conocemos -insistimos que nada se sabe de las familias de indios-sólo tres parecen no tener parentesco entre sí, aun cuando obviamente parecen estar emparentadas con otras familias cercanas (como los de la calle anterior, la Primera de Acatzingo). En la gráfica 11 hemos incluido tres gráficas para ver de qué modo se relacionan en esta calle las ocupaciones, las categorias socioétnicas, $e$ incluso los apellidos.

Los casilleros correspondientes a indios estan vacíos en las gráficas de ocupaciones y de apellidos, pues el censo no trae, como ya hemos dicho, las ocupaciones ni los apellidos para los indígenas (éstos aún no poseen, en su mayor parte, un auténtico "apellido"). Hay que subrayar además que to. 
das estas casas están contiguas -o enfrentadas, pues nuestra gráfica es una representación lineal ideal- en la misma calle y que, por supuesto, hasta el momento no podemos saber hacia dónde dan los fondos de las respectivas casas, es decir, quiénes son sus ve. cinos por los fondos. De más está decir que la mezcla de etnias y ocupaciones es algo bastante evidente en este caso, como en otros.

Aquí toda idea de diferenciar radicalmente las ocupaciones $o$ la residencia partiendo de la condición étnica, es un ejercicio completamente ilusorio.

\section{CONCLUSIONES}

Parece obvio entonces que, hablando del espacio urbano de México a fines del XVIII, antes o junto a la instancia de calificación étnica existe la percepción de una instancia social -lo que el censista de 1791 llamó "gente común" y otras fuentes, como vimos, llaman "pueblo bajo" o calificativos similares- que tiene ya la particularidad de predeterminar los límites en los cuales se encuadrará al individuo. Tanto al "calificante" como al "calificado", le resulta quizá menos importante el adjetivo elegido que la realidad social concreta de ejercer un oficio determinado, tener un lugar específico donde vivir dentro de la ciudad, manifestar una forma peculiar de vestir y de hablar.

- Ello por supuesto no implica, como decimos en las primeras páginas de este artículo, que los prejuicios raciales o étnicos se hayan borrado ni mucho menos -francamente, ¿qué sociedad pue- de hoy en día tirar la primera piedra en este sentido? ¡El espectáculo lamentable que hoy ofrecen los Balcanes y Europa central, nos parecen un marco apropiado para entender la actualidad del problema!-, sino que éstos han amenguado su papel determinante en el sistema de percepción de la sociedad en cuestión. Este sistema ahora se ha vuelto más complejo. Es decir, no por ejercer el oficio de herrero o de tejedor, el individuo es calificado automáticamente de "castizo" o "mestizo", aun cuando una proporción importante, pero ya no mayoritaria, de los tejedores y los herreros lo son. Y por otro lado, no basta ahora "el aspecto", co. mo dice algún testigo, para encuadrar a una persona en un sector determinado de la sociedad.

De todos modos, el problema más serio sigue abierto: ¿cómo llegar al nudo de la cuestión, es decir, a la autoclasificación, sin olvidar, por supuesto, la relevancia de "la mirada del otro", que sigue siendo un aspecto muy importante de la cuestión?

Los datos históricos, lamentablemente, muy pocas veces nos permiten demasiadas certezas al respecto. Los testamentos son en ese sentido una fuente muy rica, pero una serie de razones (relación entre datos cualitativos y cuantitativos, la extensión bastante limitada de la fuente -socialmente hablando-, etc.) hacen de todos modos muy dificil su utilización. Las preferencias matrimoniales son también una guía relevante, como vimos. ¡Pero, atención!, "uno no se casa con cual. quiera $^{n}$, por tanto la preferencia matrimonial es un resultado más que una causa del mestizaje cultural. Adèmás, 
no sabremos nunca y para cada caso si la notación de la calidad étnica es un calificativo otorgado por el cura o es una verdadera autoclasificación, con lo que casi volvemos al punto de partida.

En una palabra, ni: "razas" (¿definidas cómo y por quién?) ni clases económicas supuestamente "objetivas", sino un complejo sistema de representación social, en el cual, los elementos de calificación socioétnica se basan en una serie de variables que van desde el "aspecto" hasta la ocupación ejercida, pasando por la lengua, la ubicación habitacional en la ciudad y el grado de integración en el universo de valores de los sectores dominantes. Todo esto hace de un individuo, generalmente para los otros y en un lugar dado y un momento determinado, un "indio" o un "criollo". Pero, además, ese es un proceso que se halla continuamente en movimiento: los límites de la identidad étnicosocial -aun los públicamente autoasumidos- son lábiles y cam: biantes, procediendo por agregaciones, alteraciones y superposiciones en forma constante y siempre inacabada.

\section{BIBLIOGR AFÍA}

-Aguirre Beltrán, Gonzalo, La población negra de México, 1519-1810. Estudio etnohistorico, Fondo de Cultura Económica, México, 1946.

-Amselle, J.L., Logiques mêtisses. Anthropologie de l'identité en Afrique et ailleurs, Bibliothèque Scientifique Payot, $\mathrm{Pa}$ rís, 1990.

- y E. M'Bokolo, Au coeur de l'ethnie, Editions de la Découverte, París, 1985.
-Anderson, R., "Raza, clase y capitalismo durante los primeros años de la independencia", en Carmen Castañeda (comp.), Elite, clases sociales y rebelión en Guadalajara y Jalisco, siglos XVII y XIX, El Colegio de Jalisco, Guadalajara, 1988, pp. 59.72 .

-Barth, F. (comp.); Los grupos étnicosy sus fronteras, Fondo de Cultura Económica, México, 1976.

-Bouglé, Essais sur le régime des castes, París, 1908.

-Brading, David A., "Grupos étnicos, clases y estructura ocupacional en Guanajuato, 1792", Historia Mexicana, vol. xxI, (3) núm. 83, enero-marzo 1972.

-Castillo Palma, Norma A., "Mestizaje y matrimonio mixto en Cholula, 1649 1789", UnM-Iztapalapa, mecanog., s/a.

-Chance, John K., "The ecology of race and class in late colonial Oaxaca", en D. Robinson (comp.), Studies in Spanish American Population History, Westview Press, Boulder, 1981.

-Chance, John, "Estate and class in a colonial city: Oaxaca in 1792", Comparative Studies in Society and History, vol. 19, núm. 4, 1977, pp. 454-487.

- Razas y clases de la Oaxaca colonial, Instituto Nacional Indigenista, México, 1982.

-Dumont, L., Homo hierarchicus. Le systéme des castes et ses implications, Gallimard, París, 1979.

-Grajales, Agustín, "Estructura ocupacional de una villa agrícola y artesanal de la Nueva España: Atlixco, Puebla, 1792", ponencia presentada en el Congreso sobre Historia de la Población en América Latina, Ouro Preto, 1989.

-Lipschutz, A., El problema racial en la conquista de América, México, 1975.

- Martínez, Hildeberto, Tepeaca en el siglo XVI. Tenencia de la tierra y organización de un señorío, Ediciones de la Casa Chata, México, 1984.

-McAlister, L., "Social Structure and social change in New Spain", Hispanic American 
Historical Review, vol. x.m, núm. 3, 1963.

-McCaa, R., "Modeling social interaction: marital miscegenation in colonial Spanish America", Historical Methods, vol. Xv, núm. 2, 1982.

_, Schwartz, y Grubessich, "Race class in colonial Latin America: a critique", Comparative Studies in Society and History, vol. Xxi, núm. 3, 1979.

-Mörener, Magnus, La mezcla de razas en la historia de América Latina, Paidós, Buenos Aires, 1969.

- "Etnicidad, movilidad social y mestizaje en la historia colonial hispanoamericana", en J. Alvarsson y H. Hora (comps.), Etnicidad en Latinoamérica, CELAS, Uppsala Universitet, 1990.

- "Historia social hispanoamericana de los siglos XVIII y XIX: algunas reflexiones sobre la historiografia reciente", Historia Mexicana, vol. xIII, (2), núm. 166, 1992.

-Nutini, H. G. y L. I. Barry, Los pueblos de habla náhuatl de la región de Tlaxcala y Puebla, Instituto Nacional Indigenista, México, 1974.

-Pescador, Juan Javier, "La nupcialidad urbana preindustrial y los límites del mesti- zaje: características y evolución de los patrones de nupcialidad en la ciudad de México, 1700-1850", Estudios Demográficos y Urbanos, núm 19, 1992.

-Rabell, Cecilia, "Matrimonio y raza en una parroquia rural: San Luis de la Paz, Guanajuato, 1715-1810", Historia Mexicana, vol. XI.I (1), núm. 165, 1992.

-Schnapper, D., "Les limites de la démographie des juifs de la diaspora", Revre Française de Sociologie, vol. XxvIII, 1987, pp. 319-332.

-Seed, Patricia, "Social dimensions of race: Mexico city, $1753^{\prime \prime}$, Hispanic American Historical Review, vol. LXII, 1982.

- y P. Rust, "Estate and class in colonial Oaxaca revisited", Comparative Studies in Society and History, vol. Xxv, núm. 4, 1983.

-Stolke, V., Racismo y sexualidad en la Cuba colonial, Alianza, Madrid, 1992.

-Thompson, E. P., Tradición, revuelta $y$ conciencia de clase, Grijalbo, Barcelona, 1979.

-Wu, Celia, "The population of the city of Queretaro in $1791^{n}, J L A S$, vol. XVI, núm. 2,1984 . 